\title{
1968: las expectativas de Lyndon B. Johnson
}

Cristina González Ortiz ENEP-ACATLÁN

\begin{abstract}
Pormenorizada explicación de las causas que condujeron al presidente Johnson a retirarse de la contienda electoral de 1968 y, con ello, allanar el camino para la postulación de Robert Kennedy.
\end{abstract}

$\mathrm{E}$ n noviembre de 1964, Lyndon B. Johnson ocupó nuevamente la presidencia de Estados Unidos con un landslide, palabra que en el lenguaje político norteamericano significa más de un $60 \%$ del voto popular. Se vio favorecido con un Congreso de mayoría demócrata con el que emprendió una exitosa tarea legislativa que lo convirtió en el presidente de la nación que más se ha distinguido en el terreno de los derechos civiles y de la seguridad social. Sin embargo, poco le duró a Johnson el sabor de este triunfo que había hecho suyo, con tanto empeño y en condiciones tan adversas, sobre todo, si consideramos que destacó con méritos propios del ilusorio pero cautivante ambiente de Camelot que lo había precedido.

Dos años después, tras las elecciones de 1966, el partido demócrata perdió varias curules en el Congreso y algunas gubernaturas. Además, las críticas al gobierno proliferaron y notardaron en dejarse sentir las protestas y motines con motivo de la oposición a la guerra de Vietnam: También afloró el malestar por las exageradas esperanzas que no alcanzaban a cumplirse y que se habían puesto en el proyecto de Johnson de la Gran Sociedad, la más ambiciosa legislación encaminada a hacer cumplir los derechos civiles y a combatir la pobreza. Ante el reto, el equipo del presidente se preparó planeando la que pensaban sería una eficaz campaña electoral 
que conseguiría, en el otoño de 1968 , la permanencia de Johnson por otros cuatro años más en la Casa Blanca.

Sin embargo, cuando ya se habían iniciado las convenciones primarias del partido demócrata y para sorpresa no sólo de la nación entera, sino también de algunos de sus más íntimos colaboradores, el 31 de marzo de 1968, Johnson anunció que no participaría en la contienda electoral. ¿̨Qué llevó a Lyndon B. Johnson a tomar esta trascendental decisión? De la posguerra a nuestros días, pocos años se han fijado más en la conciencia de los norteamericanos, que el de 1968 por la serie de eventos dramáticos que lo colmaron. Han transcurrido ya más de 20 años y mucho se ha escrito y se sigue aún escribiendo para explicar, o al menos, comprender este último año del gobierno de Johnson.

Gracias a la generosa invitación de la Universidad de Texas en Austin y de la Lyndon B. Johnson Library, tuvimos la oportunidad de consultar los archivos de esta última. Incitados por lo repentino del anuncio.de Johnson de no participar en la campaña presidencial, decidimos estudiar en sus archivos cómo se habían vivido en la Casa Blanca los asuntos políticos relacionados con las vicisitudes del partido demócrata, las fluctuaciones de la popularidad del presidente y los preparativos de la campaña electoral de 1968 , que de hecho se iniciaron tras el revés de 1966.

Nuestro primer contacto con el tema se dio a través de los documentos de Marvin Watson. Watson fue el coordinador de la candidatura de Johnson en la convención demócrata de 1964, asistente especial del presidente a partir de 1965 y después jefe de los funcionarios de la Casa Blanca. Entre sus múltiples funciones desempeñó también la de enlace entre el presidente y el muy debatido
Comité Central del Partido Demócrata (DNC). Mayor fue todavía el provecho que pudimos obtener de la documentación de Watson, gracias a la orientación y material proporcionados con liberalidad por el doctor Lewis Gould del Departamento de Historia, buen conocedor de la poco llamativa pero eficaz labor de Watson, sobre la que ha escrito varios artículos. Por indicación de Gould, consultamos también los documentos relativos a los asuntos políticos de los legajos correspondientes a las secciones del Ejecutivo y Generales, incluyendo los archivos confidenciales referentes a la política del Partido Demócrata.

El volumen dela información contenida en los legajos consultados iba en aumento a medida que corrían los meses de los años estudiados. Hay muy escasos documentos referentes a la campaña de 1964 y su número aumenta ligeramente en la campaña del 66. No hay, sin embargo, punto de comparación entrela información que se tiene acerca de estas dos campañas con la muy abundante que encontramos en los años de 1967 y los primeros meses de 1968. Abundancia evidente de la inquietud e incertidumbre políticas.

Vista en su conjunto, la información es de muy variada índole. Abarca las sugerencias hechas al presidente por sus consejeros y sus ayudantes; la correspondencia que se recibe en la Casa Blanca de congresistas, gobernadores, líderes sindicales y público en general, en la que se opina sobre las políticas del Partido Demócrata en sus niveles local, estatal y federal; la imagen del presidente; la actitud de los jóvenes y los detractores de la guerra de Vietnam; lo que la prensa había publicado a favor y, sobre todo, en contra del presidente; el posible candidato republicano y, por último, el tema que parece inquietar más, el de las ambiciones del senador Robert Kennedy que no parecía hacer otra 


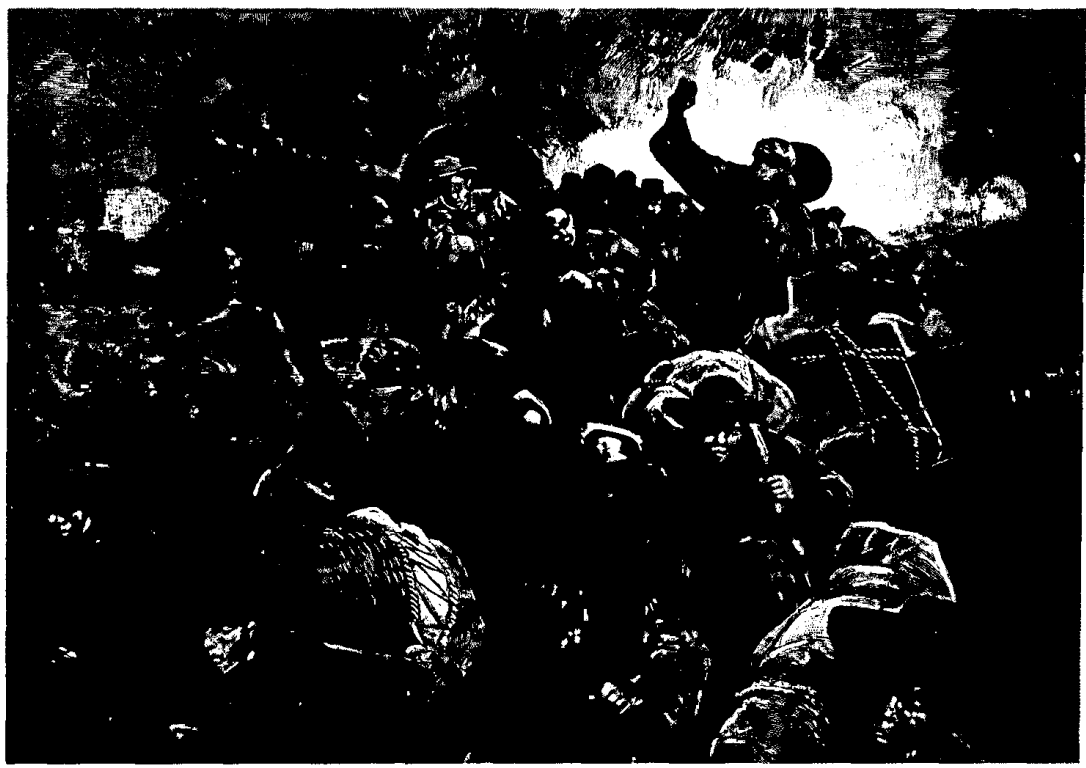

cosa que labrarse una imagen amenazadora, con ellegado de su difunto hermano. Además de esta rica correspondencia, abundan las encuestas hechas por diversas agencias, ya sea para la prensa o por encargo expreso de la Casa-Blanca, que evalúan la popularidad de Johnson y su posición frente a supuestos rivales, tanto demócratas como republicanos.

La política, rama de la actividad humana, de por sí tan compleja, lo fue todavía más en esa inmensa nación de cerca de 200000000 de habitantes. De entre ellos, un buen número gozaba de un satisfactorio nivel de vida, mismo que se sentía amenazado por el aumento de la inflación. Habían renacido también las viejas inquietudes que con renovado brío volvían a turbar las conciencias: la injusticia de una guerra que se peleaba al otro lado del mundo y que se volvía cada vez más impopular; las diferencias raciales cuya tensión había desembocado en la violencia; y la pobreza que no podían desterrar. Los jóvenes universitarios, que sí gozaban de los beneficios de la riqueza de su nación, se rebelaban y buscaban nuevos cauces para sus energías y creatividad. En suma, la conciencia de deficiencias incompatibles con los ideales tradicionales de la nación.

No se nos escapa el hecho de que había muchas fuerzas en juego difíciles de aquilatar y que, nosotros sólo trabajamos con la visión de un fragmento de esa compleja realidad, la que quedó en ciertos documentos de la Casa Blanca recogidos en los archivos. Con el agravante, además, de que pocas veces conocimos la reacción que la información recibida provocaba; más bien la intuimos. A las sugerencias que Watson hacía al presidente, éste casi siempre estaba de acuerdo y no hacía comenta- 
rios; en algunas ocasiones las rechazaba $y$, muy raras veces, anotaba de su puño y letra su franco parecer. También estamos conscientes de que la información registrada en los archivos es sólo una parte de la que se recibía en la Casa Blanca y, muy probablemente, no la más importante. Una buena parte puede estar todavía en legajos que no se han abierto al público. Otra, ni siquiera se registró. Encontramos dos o tres comunicados de John Connally y Jim Rowe, pero nada de amigos tan cercanos a Johnson como Abe Fortas, Ed Weisl o

0 Clark Clifford. Escasas referencias a Arthur Krim, el hombre que manejaba las finanzas del partido demócrata; pese a su gran influencia, sus opiniones no se registraron.

Por abundante y sugestivo que sea nuestro material, no pretendemos reconstruir, a partir únicamente de éste, la crisis del partido demócrata y la agonía por la que pasó Johnson, antes de tomar la decisión de marzo de 1968. Sin embargo, tras el estudio de los documentos, vimos que éstos no sólo no contradecían la versión historiográfica más aceptada, sino que la confirmaban ampliamente. Además, esta información posee -de ahí la razón para justificar la necesidad de su estudio-, la frescura que da la espontaneidad del momento presente, tan cargado de dudas, esperanzas, temores e incertidumbre. Asombra el confuso espectáculo de tantos hombres trabajando por una causa cuyo control estaba más allá de sus fuerzas y cuyo fracaso no acababa aún de ser escudriñado. Fracaso con el que se dio fin a las esperanzas de los políticos liberales, al movimiento de los derechos civiles y a la "generosa visión social de Lyndon B. Johnson". ${ }^{1}$

\footnotetext{
${ }^{1}$ Lance Morrow, "1968", Time, 11 de enero de 1988. La traducción de las citas es nuestra.
}

SUGERENCIAS Y POLÍTICAS PRELIMINARES para la campaña de 1968

En la escasa información que se encuentra en los legajos en vísperas de las elecciones de 1966, el sentir general es de confianza. Empero, no faltan los que observan con preocupación la misma confianza de la que también daban muestra los republicanos; los que estaban disgustados porque Johnson quería controlar al partido demócrata desde la Casa Blanca y los que, con temor, denunciaban todos los movimientos de Robert Kennedy, por parecerles que lo encaminaban hacia la próxima nominación presidencial.

Sin embargo, es sólo después de conocido el resultado de las elecciones, cuando se comienza a buscar a los culpables. La mayor parte de las críticas apuntan al DNC. También se hace palpable el malestar que Johnson experimentaba ante los periodistas. De ahí que le complaciera el tener en su haber un número mayor de conferencias de prensa que su antecesor, cuya imagen siempre trató de superar, y para que no se le criticara por eludir los medios de comunicación. ${ }^{2}$

Ahora bien, los resultados de las elecciones parecían más optimistas vistos a través de la estadística. Ni habían triunfado los republicanos ni habían sido derrotados los demócratas; simplemente se había regresado a los patrones normales de votación. Se comparó el $61.1 \%$ obtenido por Johnson en 1964 y el $60.8 \%$ de Franklin D. Roosevelt en 1936, con las curules que ambos perdieron en el Congreso en las siguientes elecciones: 71 en 1938 y 47 en 1966: Johnson salía muy bien librado. La explicación de este fenómeno, decían, no

\footnotetext{
${ }^{2}$ Al presidente, confidencial, s.f., Archivos confidenciales, FG 1, President of the United States (1967) Box 16.
} 
tenía que ver con políticas específicas o con la conducción de las campañas electorales:

Entre más grande es la concurrencia en una elección nacional, mayor es la proporción de sufragios de votantes marginales, de gente que tiene una endeble identificación de partido, relativamente poco interés político intrínseco y poca información política. A menor concurrencia, mayor será la cantidad de votos de la gente con lealtad partidista definida y más cerradamente se aproximará la división de partidos a la "fuerza de votación normal". ${ }^{3}$

En el primer caso se situaba la elección de 1964 y en el segundo la de 1966. Otro análisis de carácter tambiên muy tranquilizador, decía que no era de llamar la atención lo obtenido por los republicanos. ${ }^{4}$

Sin embargo, a John P. Roche, consejero especial en la asesoría de discursos, nole consolaba la interpretación estadistica. No habían sido derrotados "por alguna fuerza histórica abstracta" sino por republicanos de carne y hueso. Consideraba que muchas curules las habían perdido por falta de organización en el partido. Además, como algunos gobernadores se habían mostrado muy críticos en una reciente reunión tras la derrota, Roche le aconseja a Johnson que cuando los gobernadores volvieran à reunirse "para quejarse de la vida", les recordara que no era responsabilidad del DNC organizar el partido a nivel estatal: "simplemente están descargando en usted la responsabilidad de su propia incompetencia para organizarse. 15

${ }^{3}$ A Bill Moyers, 27 de diciembre de 1966, EX PL 2 Box 87.

${ }^{4}$ Fred Panzer a George Christian, 16 de diciembre, 1966, EX PL 2 Box 87.

5ohn $P$. Roche al presidente, 21 de diciembre de 1966, EX PL 2 Box 87.
Otra consecuencia de las elecciones fue que se acentuaron los rumores de que Johnson no participaría en la contienda de 1968. Inmediatamente trató de disiparlos Marianne Means, periodista amiga de la administración y de la que más artículos se encuentran en los legajos:

Todos los hechos parecen coincidir en que el presidente Johnson tiene firmes intenciones de lanzarse a un segundo término. Su salud es excelente, su única preocupación en la vida fuera de su familia es la política y el gobierno; no tiene entretenimientos que lo distraigan en caso de retiro. De hecho, él sabe muy bien que fuera del servicio público estaría aburrido $y$ frustrado. ${ }^{6}$

Por otro lado, concluye Means, si Johnson se retiraba, le daba a Robert Kennedy la oportunidad de nominarse, lo que no era un "proyecto conveniente" para el presidente.

Al mismo tiempo que se analizaba el resultado de las elecciones, comenzaron a planearse las estrategias para el 68 , de acuerdo con las críticas que se habían recibido. Como hemos dicho ya, preocupaba sobre todo, la situación del partido demócrata. En el tono de los comunicados, salvo algunos procedentes del propio DNC,' no hay confianza y se manifiesta una gran incertidumbre respecto a los resultados que se podrían obtener en el futuro. Parecía que se había. perdido el tiempo y se encontraban rezagados con respecto a los republicanos. Muchos consideraban que dos años ya no serían suficientes para reorganizarse

\footnotetext{
6 Marianne Means, Washington, 15 de diciembre de 1966, EX PL 2 Box 87.

' Los que trabajaran esa temporada en el DNC deberian sentirse orgullosos de pertenecer a un "first class team". John Criswell a Marvin Watson, 16 de mayo de 1967, EX PL Box 1.
} 
y recolectar el dinero necesario. ${ }^{8}$ Más dificil aún era luchar contra el desprestigio del partido:

... nuestro partido sufre de lo que parece ser un deterioro en la imagen pública respecto a la ley y el orden. Desde la mafia, pasando por Bob Baker, la contaminación de los ríos, hasta las manifestaciones raciales en Newark y Detroit, se duda de la habilidad del Partido Demócrata para encontrar soluciones reales frente al crimen, las manifestaciones públicas, los abusos, sea o no cierto. ${ }^{9}$

Las opiniones coincidian en que con urgencia debían reconstruirse las organi-

${ }^{8}$ Charles M. Smith a Milton Semer, 5 de diciembre de 1966; Robert E. Kintner al presidente, 2 de diciembre de 1966, EX PL 2 Box 87.

${ }^{9}$ William L. Guy al presidente, 16 de agosto de 1966, EX PL 2 Box 88. zaciones del partido desde el nivel local al federal y poner en contacto al DNC con los directivos estatales y locales. Para ello se necesitaban hombres, verdaderos líderes políticos que ejercieran el patronazgo y, muy ligado a esto, se necesitaba, sobre todo, dinero; dinero sin el cual parece que no existe un método efectivo de patrocinio político legítimo. ${ }^{10}$ No se dan detalles sobre la manera de ejercer este patrocinio político, tipo de información que lamentablemente está ausente no sólo de este archivo, sino, por lo general, de todos. Únicamente se menciona el malestar de algunos líderes quejosos que tratan de

${ }^{10}$ Robert E. Kintner al presidente, 2 de diciembre de 1966, EX PL Box 87; Henry H. Wilson Jr. al presidente, 21 de enero de 1967, EX PL 6-2 Box 116; Charles M. Smith a Milton Semer, 5 de diciembre de 1966, EX PL 2 Box 67; James Cuff O'Brien, 22 de agosto de 1967, EX PL 6-2 Box 116.

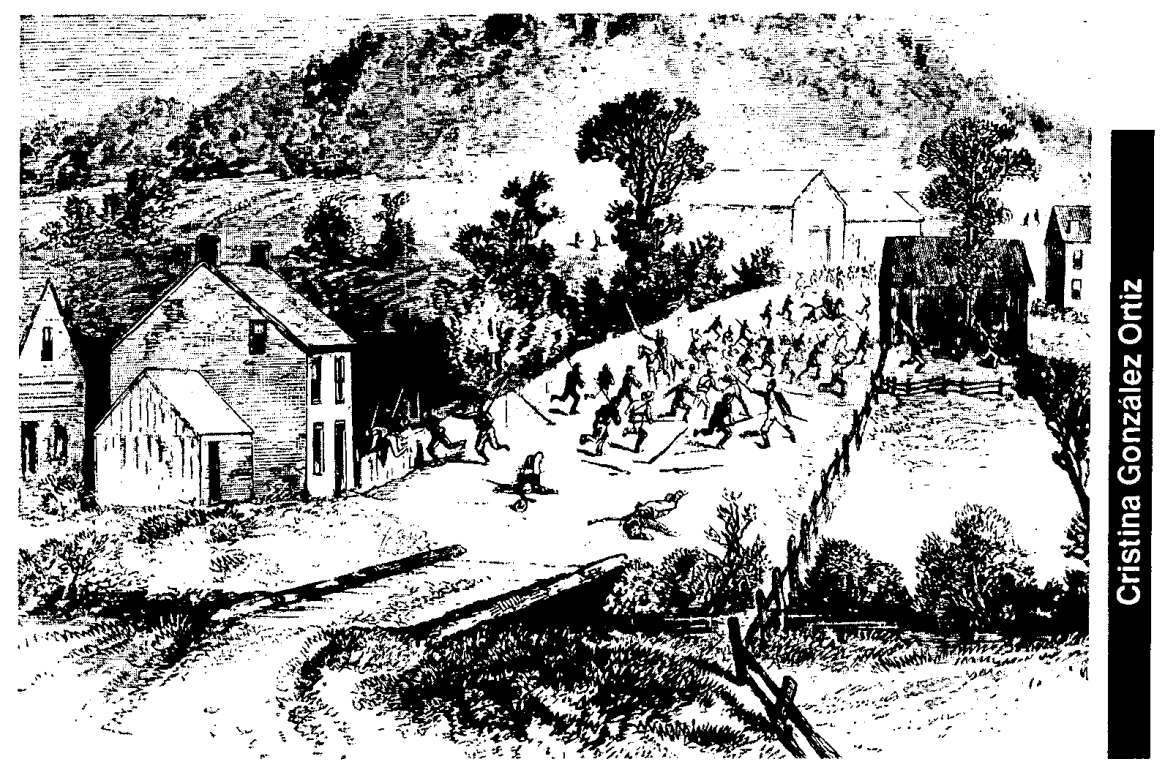


remediar su falta de poder llamando la atención con críticas al partido. ${ }^{11}$ Así, se recomienda no olvidarse de los colaboradores partidistas:

... se debería de otorgar un mayor número de nombramientos políticos que de servidores públicos en los mandos medios y niveles inferiores. Ahí está la gente que representa a la administración en los pueblos y las ciudades. Con demasiada frecuencia se escucha el comentario de que esta administración está compuesta por gente con poca imaginación, aburrida y carente de sensibilidad política. ${ }^{12}$

Tampoco hay sugerencias específicas sobre cómo recolectar fondos, salvo el proponer que Arthur Krim se encargue de los líderes obreros y empresariales, de quienes procedían los grandes donativos, o el suprimir el President's Club para crear, en su lugar, un organismo de base más amplia que permitiría recolectar más dinero. Es más tarde cuando se propone el grupo Ciudadanos Demócratas para la elección de $1968 .^{13}$

Existe, en cambio, algo de información sobre las visitas de los líderes del partido a los estados que habían comenzado a organizar la Casa Blanca y el DNC. Estas visitas debían iniciarse en zonas como Nueva Inglaterra en donde contaban con

1 Albert S. Porter a Hubert Humphrey, 21 de diciembre de 1966, EX PL Box 1.

12 Documento sin datos, EX PL 2 Box 89. La única fecha que contiene es la de su recibo en los Central Filesen mayo de 1968, pero parece que fue escrito mucho antes, recién celebradas las elecciones de 1966 , ya que para su autor, el propósito del documento era "proporcionar el resultado de las elecciones de 1966 y las ideas de los siguientes dos años".

${ }^{13}$ Kintner al presidente, 2 de diciembre de 1966 , EX PL 2 Box 67; Lincoln (Mickey) Polan a Marvin Watson, 8 de diciembre de 1966, EX PL 2 Box 87 y 26 de julio de 1967, EX PL Box 1. amigos. Los líderes locales no sólo se sentirian alentados por la deferencia de que eran objeto, sino también más comprometidos al resaltarse la importancia de su colaboración. Ahora, debidamente instruidos, estarían mejor capacitados para responder a preguntas sobre temas muy delicados, las que antes les hacían caer en situaciones embarazosas, porque no se les habían proporcionado los argumentos adecuados para responder con habilidad. ${ }^{14}$

Son muchas las voces, veladas o no, que piden se retire a John Bailey de la presidencia del DNC. Pese a que no había comentarios a su favor, permaneció en su cargo hasta después del mensaje de Johnson, de marzo del 68. Se le critica a Bailey el ignorar y no consultar a las organizaciones estatales y locales: "hemos sido ignorados, explotados, insultados y olvidados desde que Johnson fue electo". Se propone, para demostrar el interés de la Casa Blanca en los líderes locales, invitarlos a charlar en privado con el presidente, para que se sientan "involucrados, en contacto, comprometidos". 15

Ante las críticas que recibía la legislación de la Gran Sociedad, se consideró mejor no insistir mu cho en ella y prestarle más atención al mejoramiento de los programas ya aprobados. Las reformas no se habían hecho efectivas dado su número y el corto plazo en el que habían sido promulgadas; esto había provocado

${ }^{14} \mathrm{John}$ Criswell a Watson, 28 de marzo de 1967 , EX PL 6-2 Box 116; Sherwin Markman a Watson, 31 de agosto de 1967, EX PL Box 1; William Connell a Watson, 29 de agosto de 1967, EX PL Box 1.

${ }^{15}$ George Reedy al presidente, 10 de noviembre de 1966; Lincoln Polana Watson, 8 de diciembre de 1966; Kintner al presidente, 2 de diciembre de 1966 , EXPL 2 Box 87. Albert S. Porter a Hubert Humphrey, 21 de diciembre de 1966; Grace Halsell al presidente, 18 de mayo de 1967, EX PL Box 1.

\section{1}

1

3 
los motines sufridos en algunas ciudades durante los últimos veranos, amén del descontento en amplios sectores de la sociedad. Destacan las amargas quejas que entre los mismos líderes sureños provocaba la legislación de los derechos civiles:

Cuál es su mensaje a los demócratas leales que en el arraigado sur desesperadamente luchan por mantener un partido demócrata fuerte, mientras que sabemos que algunas de las políticas del Partido Nacional Demócrata están en conflicto absolutocon la cultura y la filosofía de la gran mayoría de los ciudadanos votantes del sur. ${ }^{16}$

Por medio de la Casa Blanca se debía proporcionar la información requerida por los miembros del partido. Al contar con todos los datos y cifras del gobierno federal, la Casa Blanca se convertiría en una organización de servicio y no parecería ya tan inaccesible. También mediante el gabinete se podía hacer propaganda de los aciertos de la administración. Se llegó a proponer, con este objeto, que el gabinete se reuniera dos veces al mes en una especie de consejo de directores de las empresas. ${ }^{17}$

Los funcionarios de la Casa Blanca también debían asistir a los mítines políticos estatales. Sobre todo, de estados como California y Nueva York a los que no se podía perder de vista. A este último

${ }^{16}$ Reedy al presidente, 10 de noviembre de 1966; Charles M. Smith a Milton Semer, 5 de diciembre de 1966; Lincoln Polan a Watson, 8 de diciembre de 1966, EX PL 2 Box 87; Albert S. Porter a Hubert Humphrey, 21 de diciembre de 1966, EX PL Box 1; H.R. Burnham al presidente, 1 de octubre de 1966 , EX PL 6-2 Box 116.

17 Reedy al presidente, 10 de noviembre de 1966; Joe Califano al presidente, 10 de junio de 1966; Kintner al presidente, 1 de junio de 1967, EX PL 2 Box 87; memorándum s.n., 10 de abril de 1967 , EX PL 6-2 Box 116. se le consideraba muy peligroso por sus círculos liberales y el poder de sus medios de comunicación: difundian a nivel nacional el más insignificante pronunciamiento hecho por un club político de escasos 40 miembros. $^{18}$

Preocupaba mucho quiénes iban a pronunciar los discursos de propaganda y cómo se les iba a programar. Se pensó que los más indicados serían los miembros del gabinete coordinados de alguna manera. Watson y Criswell, quien representaba al DNCen la Casa Blanca, veían con simpatía la creación de un Comité Asesor en Comunicación. ${ }^{19}$

Necesitaban también portavoces en el Congreso que defendieran las politicas de Johnson y contrarrestaran la actividad de congresistas como Gerald Ford. Tampoco faltó quien pensara en la necesidad de un buen "golpeador" para responder a los ataques de la prensa:

... un golpeador para devolver los golpes frontal y públicamente a los republicanos mientras éstos afilan sus hoces para usarlas en usted [Johnson] [...] debe existir un hombre bendecido por la Casa Blanca para pegar fuerte y al que la prensa llegará a señalar como la voz distintiva de la Administración. ${ }^{20}$

Otra tarea era mejorar la poco cordial relación entre el presidente y la prensa. Para cuidarse de ella, Johnson ya no

\footnotetext{
${ }^{18}$ John Criswell a Watson, 28 de marzo de 1967 ; Edward N. Costikyan a John Bailey, 21 de junio de 1967, Archivos confidenciales, PL/ST 15-32 Box 77; James Cuff O'Brien a John Criswell, 28 de junio de 1967, Archivos Confidenciales, PL/ST 1-14 Box 76.

${ }^{19}$ Memorándum s.n., 10 de abril de 1967, EX PL 6-2 Box 116; Jack Brooks a Douglas Cater, 23 de junio de 1967; Criswell a Watson, EX PL Box 1; William Connell a Watson, 1967, EX PL6-2 Box 116.

20 Ben Wattenberg al presidente, 25 de marzo y 15 de septiembre de 1967; Kintner al presidente, 2 de diciembre de 1967, EX PL Boxes 87 y 88 .
} 
debía hablar de lo que él podía hacer, sino de lo que podía hacer el partido. Pero precisamente, en el mismo momento que se trató el problema de los medios de comunicación, The National Observer había pedido unas fotos recientes del presidente para ilustrar una historia del partido demócrata y las elecciones de 1968. En el memorándum, Johnson no sólo cruzó la palabra No, sino que añadió "no quiero mandar ninguna", como para que no quedara duda alguna de su rotunda negativa de cooperar. ${ }^{21}$

Como estrategia general de la campaña, se menciona repetidas veces la necesidad de un buen plan de registro de electores y de atraer a los jóvenes y, en general, a la gente de los suburbios. Se insiste en que el control político se encuentra en los centros urbanos y suburbanos, a los que el partido ha descuidado. El elector modelo que se describe no es joven, ni negro, ni pobre, por lo que se debía enviar el mensaje político a los blancos de edad madura y clase media. ${ }^{22}$

Con respecto a lo que podría llamarse el espíritu de la campaña, los asesores parecen estar de acuerdo en que se debe ver hacia el futuro. No decir qué se había hecho sino qué se perseguía lograr para los siguientes cuatro años. Esta estrategia se consideraba útil sobre todo, porque evitaba dar explicaciones a la defensiva. Reconocían que la retórica política no les ofrecía muchos recursos de los que echar

${ }^{21}$ Liz Carpenter a Kintner, 5 de enero de 1967 , EX PL 6-2 Box 116; Polan a Watson, 8 de diciembre de 1966; Watson al presidente, 15 de junio de 1967. EX PL 2 Box 87.

${ }^{22}$ Kintner al presidente, 2 de diciembre de 1966, EX PL 2 Box 87; John P. Roche al presidente, 16 de diciembre de 1966, EX PL 6-2 Box 116; William Connell a Hubert Humphrey, 28 de julio de 1967; Douglas Cater a Ben Wattenberg, 19 de agosto de 1967, EX PL 2 Box 87; William Connell a Watson, 29 de agosto de 1967, EX PL 6-2 Box 116. mano para defenderse porque, en realidad, el gobierno había "provocado el déficit, el Congreso se negaba a actuar con responsabilidad, la guerra se había intensificado, los impuestos, aumentado y los ghetos, explotado". Lo mejor era, entonces, recordar la grandeza y virtudes del pueblo norteamericano. ${ }^{23}$

Empero, no debían mostrar preocupación ante lo adverso de la situación. Por el contrario, debían mostrar una actitud relajada y constructiva, olvidándose de Vietnam, la prensa, el Congreso, los republicanos y la oposición entera:

La oposición debe ser tratada con tolerancia en el entendido de que la gente en la Casa Blanca está buscando la forma de guiar el destino de la nación más grande del mundo libre. Por lo tanto está demasiado ocupada como para perderse en batallas pueriles. La regla fundamental que ba definido la política en este país en las últimas tres décadas es que la grandeza, imaginación y compasión expresadas por el Partido Demócrata ha provocado sólo mezquindad, esterilidad y críticas del Partido Republicano. No existe razón para invertir los papeles en este momento. ${ }^{24}$

Todos parecen coincidir, además, en que el principal vehículo de la propaganda sería la televisión, mediante películas sobre el presidente o apariciones informales en las que Johnson expresara su punto de vista sobre la solución de los problemas de la nación. Les preocupaba, sin embargo, que el tiempo les había

${ }^{23}$ Documento sin datos, EX PL 2 Box 89, ver nota 12; Bill Graham a Douglas Cater, 8 de agosto de 1967 , EX PL 2 Box 87; Kintner al presidente, 8 de septiembre de 1967, Archivos confidenciales, PL 2 Campañas electorales, Box 77.

${ }^{24}$ Reedy al presidente, 10 de noviembre de 1966; Kintner al presidente, 1 de junio de 1967, EX PL. 2 Box 87. Cursivas en el texto original.
1 1

5 


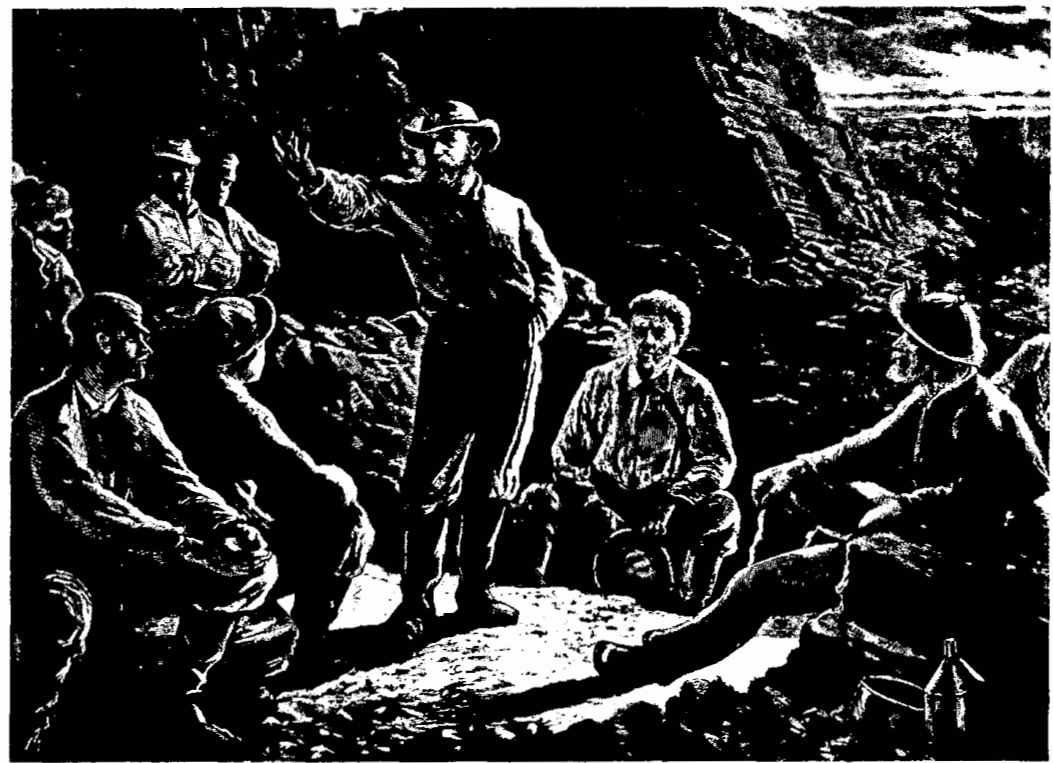

ganado y carecían de este material para la televisión. Les urgía una película

que con un poco más o menos de sutileza respondiera a las mayores críticas que se generarían en su contra. Nada mejor que una película para proyectar calor humano, integridad, sinceridad, compasión e inteligencia. $^{25}$

Por lo que se refiere al enemigo que deben combatir, dos son los más temidos: uno, el futuro candidato republicano, del que se habla poco y el otro, Robert Kennedy, de quien se expresan en tono de sobra acrimonioso, amén de que se le teme sobremanera. De los re-

${ }^{25} \mathrm{Kintner}$ al presidente, 2 de diciembre de 1966 ; William Connell a Watson, 7 de marzo de 1967; Myer Feldman a Watson, 21 de junio de 1967; Bill Grahama Douglas Cater, 8 de agosto de 1967, EXPL 2 Box 87. publicanos sólo se hacen cálculos acerca de cómo afectaría a los demócratas la postulación de tal o cual candidato. Cuando todavía los resultados de las encuestas eran muy variables, el líder de los demócratas en Vermont ya pensaba que los republicanos postularían a Nixon por lo que no debían preocuparles Rockefeller o Romney. De la candidatura independiente de Wallace, piensan que podría favorecer a los demócratas en el sur, péro no en toda la Unión, a menos que los republicanos postularan a otro neanderthal en política exterior. ${ }^{26}$ Sin embargo, el verdadero temor parecía proceder de otra fuente:

Los demócratas tienen un buen historial y un gran programa, pero esto no es sufi-

${ }^{26}$ Dan O'Brien a Joe Califano, 1 de abril de 1967. EX PL 2 Box 87; John P. Roche al presidente, 15 de marzo de 1967, EX PL 6-2 Box 116. 
ciente. Deben organizarse para impedir que los republicanos logren transmitir el desorden interno y la falta de unidad de los demócratas. ${ }^{27}$

Lo que parece marcar la diferencia más obvia entre Johnson y los Kennedy es la reluciente formación académica de los últimos y su estrecha relación con el mundo intelectual. Para algunos de los hombres de Johnson, los Kennedy gozaban de atractivo entre los intelectuales porque, con su riqueza, los patrocinaban y les otorgaban medallas. Los Kennedy financiaban el Kennedy Institute of Politics que era "más un Shangri-La que un centro intelectual de entrenamiento parasus fuerzas", además de otros comités especiales, como uno encabezado por Bill Haddad en Nueva York, que contaba con doscientos abogados.

En vista de ello, la Casa Blanca trataba de no descuidar sus relaciones con los intelectuales. Sin embargo, se sugería como estrategia, para no caer en la trampa de los Kennedy, no hacer distinciones entre intelectuales y no intelectuales dentro de la administración. Mucho menos, tratar de darle cierto aire intelectual al presidente: "usted [Johnson] provee de municiones a sus oponentes cuando da la impresión de ser diferente de lo que realmente es, un servidor público muy capaz". Por esta razón se le aconsejaba a Johnson que hablara del sistema político norteamericano desde el punto de vista de su larga experiencia y no con el lenguaje del teórico. El pueblo vería así que

Estados Unidos está mejor servido por un presidente plenamente familiarizado con el proceso político y que pueda expresar puntos de vista firmes sobre ése, mejor

${ }^{27}$ Watson al presidente, 26 de agosto de 1967 , EX PL 6-2 Box 116. que un hombre empeñado en vender un perfil clásico y nada más. ${ }^{28}$

La actividad política de Robert Kennedy comienza a criticarse más abiertamente a principios de 1967. En el mes de febrero se reciben varias quejas acerca de sus declaraciones en Francia sobre política exterior que no coinciden con la opinión de la administración. Además, en los momentos en que todos los demócratas debían presentar una misma postura frente al enemigo. Los críticos opinaban que sólo buscaba hacerse propaganda y dar "ayuda y consuelo al enemigo". ${ }^{29}$

Hacia fines de marzo, George Christian, secretario de prensa de la Casa Blanca, recibe una interesante información. Su asombrado confidente le dice estar convencido de una planeada campaña a través de la radio y de la prensa y con una fraseología muy repetitiva, a favor de Kennedy, "digamos un 'maremoto' sentimental para empujar a Bobby Kennedy a la Convención del 68". En su respuesta, Christian agradece la "muy seductora" pesquisa. ${ }^{30}$

Aunque desde febrero circulaba la propaganda de los "Ciudadanos por Kennedy y Fulbright", no se encuentran referencias escritas de los consejeros del presidente acerca de ésa, lo que no quiere decir que la ignoraran. Esta campaña de los "Citizens" tenía como

${ }^{28}$ Robert G. Claskey al presidente, 30 de enero de 1967; John P. Roche al presidente, 23 de enero de 1967; Ben Wattenberg al presidente, 25 de febrero de 1966, EX PL Box 1; Kintner al presidente, 1 de junio de 1967, EX PL 2 Box 87.

${ }^{29}$ Hubert Humphrey a Watson, 10 de febrero de 1967; Ira V. Mattheus a John J. Sparkman, 27 de febrero de 1967; Francisco Douglas al presidente, 7 de marzo de 1967, EX PL Box 1.

30 Allen Skidmore a George Christian, 29 de marzo de 1967; Christian a Skidmore, 4 de abril de 1967, EX PL 2 Box 87. 
objetivo convencer a Robert Kennedy de que contaba con el apoyo del partido demócrata y, a Johnson, de todo lo contrario. Aunque tardíamente, según los documentos encontrados, la gente de Johnson comenzó a vigilar las actividades de este grupo. En el mes de julio, un invitado a las reuniones de los "Citizens" reporta que los invitados eran gente bien vestida y que se había hablado de Vietnam; en su afán de saber más, esta persona había entablado conversación con el periodista Jack Anderson, a quien conocía por pertenecer a su misma iglesia, y le había preguntado qué tanto sabía de esta asociación, a lo que Anderson le había respondido que nada, pero que le interesaba el asunto. Ese mismo mes aparece otro detallado reporte sobre los planes de los "Citizens", que muestra ya una clara labor de espionaje de parte de la Casa Blanca. Sin embargo, al no muy ducho informante, que pertenece al DNC, no le queda claro si todo el grupo de Kennedy está a favor del proyecto o no y si, de estarlo, los "Citizens" representan o no una verdadera amenaza para Johnson. ${ }^{31}$

Dos comunicados de fines de junio se refieren a una invitación que hacen a Johnson los "Citizens", para discutir las políticas del partido demócrata para las elecciones de 1968. Además se le exige con brusquedad al presidente, una respuesta para antes del 7 de julio. No encontramos indicios de que la Casa Blanca se haya tomado la molestia de responder. ${ }^{32}$

${ }^{31}$ Darrel G. Reustrom a Spencer Oliver, 19 de julio de 1967; Spencer Oliver a John Criswell, 28 de julio de 1967, EX PL 2 Box 87.

${ }^{32}$ Martin Shepard al presidente, 26 de julio de 1967, EX PL 2 Box 87; 29 de junio de 1967, EX PL 2 Box 1 .
En el mes de agosto se reporta a Johnson lo que parece ser un cambio de actitud entre los "Citizens". En vista de los esfuerzos que se hacían para conseguir la paz, Joseph L. Rauh, que presidía el grupo Norteamericanos por la Acción Demócrata (ADA), consideraba -y era apoyado por Galbraith, Wayne Morse y McGovern-, que el atacar al presidente, nulificaba todos los esfuerzos poralcanzar la paz:

cualquièr otro movimiento que desprestigie a Johnson dentro del Partido Demócrata puede afectar los esfuerzos de paz porque ningún delegado responsable permitirá que su nombre esté conectado con movimiento alguno en contra de un presidente demócrata.

Por otro lado, como lo había pensado también la gente de Johnson, Rauh estaba de acuerdo en que la división de los demócratas sólo beneficiaría a Nixon, por lo que Kennedy tendría que apoyar a Johnson. ${ }^{33}$ Sin embargo, aunque Rauh recomendaba a los miembros de la ADA la unión de todos los demócratas, a fines de mes; Watson recibía nuevamente propaganda de los "Citizens". Y ahora en términos más agresivos: o Johnson abandonaba su política en Vietnam o su partido lo abandonaba a él. A fines de septiembre se informaba a la Casa Blanca que Charles Porter, uno de los colaboradores más cercanos de Kennedy, había estado en Nebraska auscultando el ambiente político, "y tuvo una gélida recepción de la gente del partido": Así, aunque Kennedy públicamente declaraba su apoyo al presidente Johnson, la

33 John $P$. Roche al presidente, 3 de agosto de 1967, EX PL Box 1; 16 de agosto de 1967, EX PL 2 Box 87. 
correspondencia recibida en la Casa Blanca muestra la difundida certidumbre en el ambiente político, de que Kennedy buscaría la postulación del partido demócrata en $1968{ }^{34}$

Durante estos meses en los que abundan las críticas a Robert Kennedy, sólo encontramos una propuesta de conducta frente a éste. En un memorándum confidencial se le recomienda a Johnson: "olvidar (pero no perdonar) todo el cabrioleo de Kennedy." Ya Kennedy estaba advertido que se arruinaría, junto con Johnson, en caso de hundirse éste. ${ }^{35}$

Es dificil evaluar el verdadero peso de

${ }^{34} \mathrm{~A}$ Watson, 31 de agosto de 1967; Billie Farmn a John Criswell, 15 de junio de 1967; EXPL 2 Box 1; Marty Underwood a Jim Jones, 15 de septiembre de 1967; Tom Johnson a George Christian, 29 de agosto de 1967, EX PL 2 Box 88.

${ }^{35}$ Kintner al presidente, 8 de septiembre de la amenaza de Kennedy a través de la correspondencia recibida, sobre la que, además, no existen comentarios. Sin embargo, la Casa Blanca contaba con un medio mucho más efectivo para aquilatar el reto de Kennedy, las encuestas. En los legajos revisados, los reportes sobre encuestas ocupan un espacio muy considerable. Sin embargo, los resultados de ésas no son menos contradictorios que la información detallada anteriormente, lo que no hacía, seguramente, sino aumentar la inquietud y la desconfianza entre los hombres del presidente.

Durante los primeros nueve meses de 1967, la información sobre Robert Kennedy muestra cuan rápidamente la opinión pública cambia de parecer. En enero, Robert Kintner, asistente especial

1967, Archivos confidenciales, PL 2 Campañas electorales (1967) Box 77.

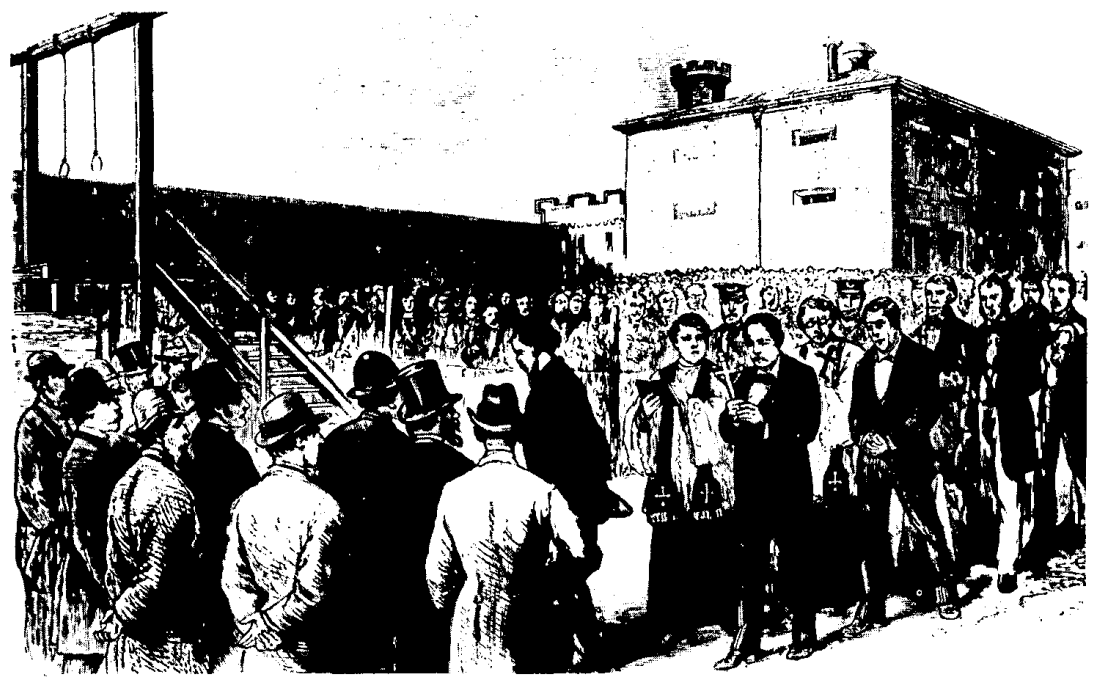


de la Casa Blanca, recibe dos encuestas, una de Gallup y otra de Harris Survey. La primera es alarmante:

$\begin{array}{lcc} & \text { Kennedy } & \text { Jobnson } \\ \text { Adultos en general } & 48 & 39 \\ \text { Demócratas } & 52 & 39 \\ \text { 21-29 años } & 67 & 26\end{array}$

Kintner pasa por alto los resultados de esta encuesta y sólo comunica al presidente los más halagüeños de la Harris Survey:

$\begin{array}{lr}\text { Enero } & 67 \\ \mathrm{~K} & \mathrm{~J} \\ 44 & 56\end{array}$

$\begin{array}{cc}\text { Noviembre } & 66 \\ \mathrm{~K} & \mathrm{~J} \\ 54 & 46\end{array}$

Estos son datos considerando a toda la población en toda la nación; la encuesta es muy detallada y da cifras por regiones, sexo, edad, raza, religión e ingresos. En casi todos estos renglones Johnson sale bien librado o el margen de ventaja de Kennedy no es muy grande:

La aparente invulnerabilidad de Robert Kennedy entre las mujeres y la gente joven parece que ha sido afectada. El es aún relativamente fuerte con estos grupos pero lo que ahora es definitivo es que está por detrás de L.B.J. ${ }^{36}$

En el mes de mayo se publica otra encuesta de la Gallup que ahora sí muestra la ventaja de Johnson sobre Kennedy y cómo éste ha ido perdiendo popularidad:

$\begin{array}{lcccc} & \text { Abril } & \text { Marzo } & \text { Febrero } & \text { Enero } \\ \text { LBJ } & 49 & 45 & 45 & 39 \\ \text { RFK } & 37 & 41 & 44 & 48 \\ \text { Indecisos } & 14 & 14 & 11 & 13 .{ }^{37}\end{array}$

${ }^{36}$ Fred Panzer a Kintner, 26 de enero de 1967; Kintner al presidente, 27 de enero de 1967, Archivos confidenciales, PL 2 Campañas electorales (1967) Box 77.

37 Panzer al presidente, 5 y 8 de mayo de 1967 , EX PL 2 Box 87.
Ese mismo mes de mayo, se considera también el impacto de Martin Luther King en la opinión pública, lo que lleva a Harris a sugerir la conveniencia de postular a Kennedy para la vicepresidencia. ${ }^{38}$

Hacia fines de septiembre, la suerte ha cambiado de nuevo. Si una encuesta parece mostrar la ventaja de que Kennedy acompañe a Johnson en lugar de Hubert Humphrey, otra le da la ventaja a Kennedy sobre Johnson:

$\begin{array}{lll} & \text { JFK } & \text { LBJ } \\ \text { Los demócratas } & 39 & 37 \\ \text { Los adultos } & 51 & 39\end{array}$

Tras analizar las variaciones desde el mes de enero, Gallup las atribuye a la baja de popularidad de Johnson y no a que efectivamente fuese más atractiva la figura de Kennedy:

Es simplemente la señal de que él [Kennedy] esta llenando el vacío que queda cuando decae la popularidad de Johnson. En otras palabras, ningún oponente, y esto parece ser cierto en las cifras del Partido Republicano, puede ganar con su programa, plataforma política o personalidad. Sólo son fuertes en tanto el presidente pierde apoyo. ${ }^{39}$

Las malas noticias parecian, entonces, no serlo tanto. Si se cuidaba la imagen de Johnson, ningún otro candidato significaba una amenaza. Lo difícil era, precisamente, cuidar esa imagen. Marianne Means le había escrito en esos días a Johnson, preocupada por el pánico de: satado en Washington debido a los rumores de posibles motines de los negros.

${ }^{38}$ Panzer al presidente, 19 de mayo de 1967 , EX PL 2 Box 87.

${ }^{39}$ Panzeral presidente, 25 y 29 de septiembre de 1967, EX PL 2 Box 88. 
Le comentaba que, aunque en su columna periodística hacía un esfuerzo por parecer racional, en privado discutía con su esposo acerca de la conveniencia de

...conseguir un rifle, proteger nuestras ventanas y despedir a nuestra sirvienta negra. No hicimos ninguna de estas cosas. Sin embargo, me alarma pensar que gente de clase media como nosotros, con las comodidades y seguridades que tenemos, pudiéraruos tener una discusión de este tipo.

Le reitera, sin embargo, su confianza y aprovecha la oportunidad, para recomendarle a su esposo por la experiencia que éste tiene en la conducción de las campañas electorales. ${ }^{40}$

Hacia fines de septiembre aparece un comunicado titulado "White Paper", que puede considerarse como un proyecto oficial para la campaña de 1968. Su autor es Lawrence O'Brien, director general de Correos, cargo tradicionalmente relacionado con el control político del partido en turno en el poder.

\section{LOS PREPARATIVOS PARA LA CAMPAÑA}

En todo el material que se encuentra en los legajos, no existe otro documento que por la riqueza de su contenido se iguale al de O'Brien. El hecho de ser, a su vez, extremadamente confidencial, indica su gran importancia.

O'Brien comienza por hacer hincapié, aunque parezca obvio, en que su objeti-

${ }^{40}$ Marianne Means al presidente, 2 de agosto de 1967, EX PL 2 Box 87. Aunque Means siempre escribe a favor de la administración, Johnson parece no confiar en los periodistas. En una ocasión en que Means pidió verlo para hablar del DNC, Johnson aceptó, pero recomendándole a Watson "no diga mucbo". Watson al presidente, 6 de enero de 1967 , EX PL Box 1. vo es conseguir la reelección de Johnson. Sin embargo, por las dificultades a que éste se enfrentaba, las medidas que debían adoptarse se salían de lo convencional $y$ "pudiesen ofender a algunas personas". ${ }^{41}$

Así y, probablemente, ante la imposibilidad de emprender a estas alturas reformas en el DNC, que parecía no convencer ya a nadie, O'Brien propone una organización por encima de ese organismo, que lo relacionaría con los comités de campaña y el Congreso. Esta nueva superestructura, la Fuerza para Organizar la Campaña (CTF), sólo trabajaría un año, a partir del día 5 de noviembre. Su director sería el responsable del registro de electores, de la distribución del material de propaganda y, sobre todo, de obtener el voto de los diferentes sectores de la sociedad: jóvenes, ancianos, mujeres, etnias, trabajadores, etcétera.

Destaca O'Brien el papel que las computadoras van ya a jugar en esta campaña. No sólo para organizar los datos de las encuestas, sino para ganar las elecciones. La programación de la computadora debería estar en manos de un político y, por el tiempo que requería programarla bien para que fuese eficaz, se debería comenzar inmediatamente. El dinero que se ahorrara con el uso de la computadora se gastaría en propaganda, sobre todo, en la televisión que era en

${ }^{41}$ Lawrence F. O'Brien, "A white paper for the president on the 1968 presidential campaign", Confidencial, 29 de septiembre de 1967, Archivos de Marvin Watson, "DNC, Rowe, O'Brien, Crooker, Criswell Operation", Box 20 p. 1. Poco antes de presentar este documento, O'Brien habia presidido la Western States Democratic Conference y enviado a Watson sus observaciones: éxito sin controversias y apoyo al presidente en Vietnam; sin embargo, muchos líderes se habíanquejado del mal funcionamiento del DNC y esta queja no era nueva. Western States Democratic Conference, 28 de agosto de 1967, EX PL Box 1.
1 


\section{SECUENCIA}

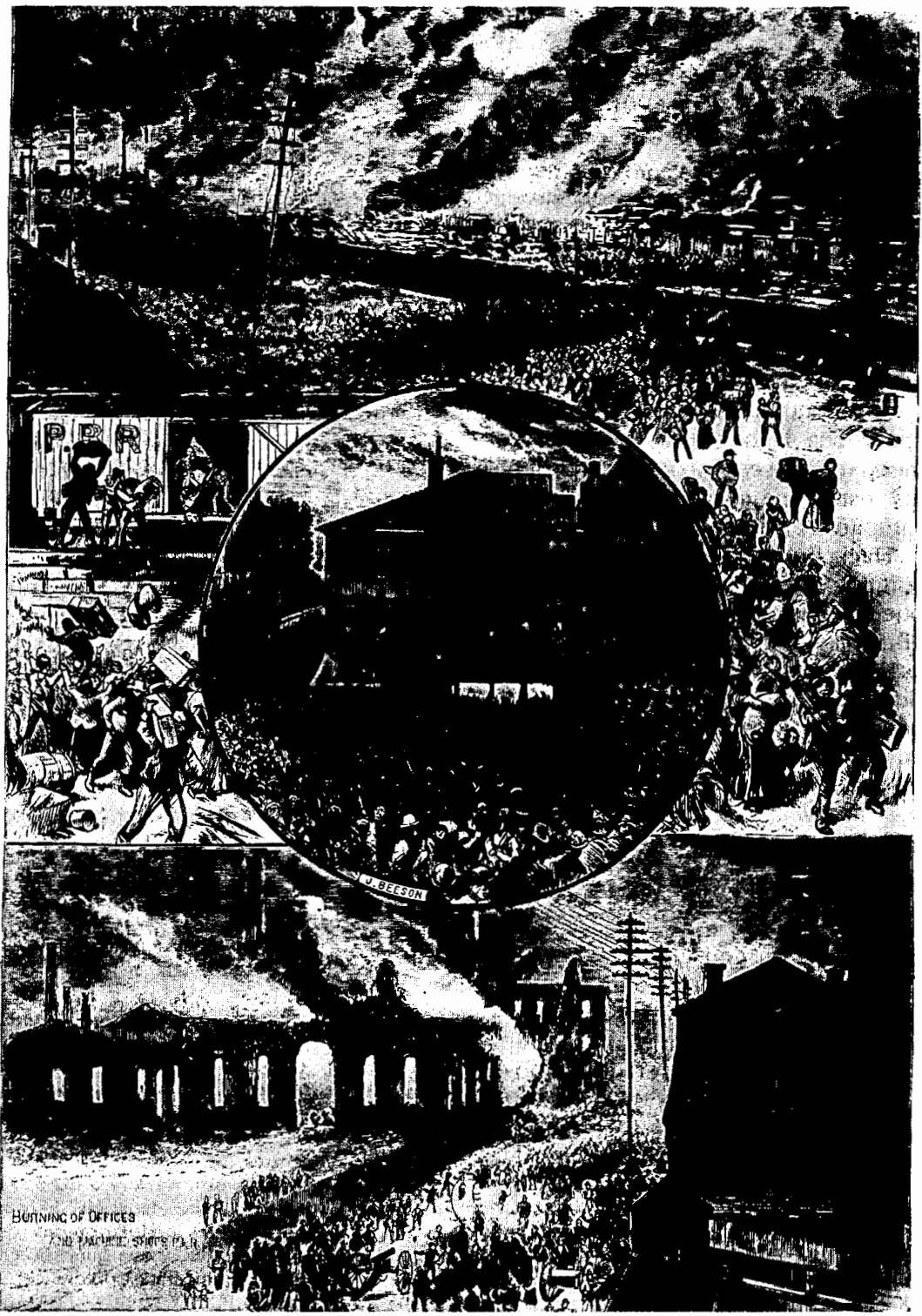


donde, profetiza O'Brien, se ganaría o perdería la campaña. Como a otros muchos, a O'Brien le preocupa también la falta de tiempo. No se tiene preparado el material para las transmisiones. Sugiere filmar, y a todo color, cuanta aparición pública hiciese el presidente. Por otrolado, todo el material impreso debería ser de buena calidad y repartirse a tiempo. Para esto se necesitaba dinero con urgencia.

Por último, en lo referente a la organización, la persona más importante de la CTF sería el director de Política y Estrategia. Él decidiría qué decir o no en los discursos y la propaganda, coordinaría a los intelectuales, vigilaría a los republicanos y supervisaría a los candidatos a diputados y senadores proporcionándoles toda la información necesaria para sus campañas.

La parte más interesante del documento es aquella en la que se plantea la estrategia a seguir ante los problemas a que se enfrentan los demócratas. O'Brien recoge muy bien el sentir de la correspondencia recibida en los meses anteriores en la Casa Blanca. El pueblo no iba a votar por lo que Johnson había hecho sino por lo que iba a hacer, por las metas que se proponía alcanzar en el futuro. Pone como ejemplo el problema más álgido al que se enfrentaban y que casi volvía insignificantes a todos los demás, Vietnam. ¿Cual era ahí la meta de Johnson? O'Brien explica: “... llegar a un cese al fuego sin comprometer nuestra razón de estar en Vietnam. Estamos ahí para detener al comunismo, para defender nuestro compromiso con la libertad."142

Por otro lado, a diferencia de las elec-

${ }^{42}$ Lawrence F. O'Brien, "A white paper..." Archivos de Marvin Watson, "DNC, Rowe, O'Brien, Crooker, Criswell Operation", Box 20. p. 26. Cursivas en el texto original. ciones de 1964, los demócratas estarían ahora a la defensiva. Es más, habría votos, no a favor de los republicanos, sino en contra de Johnson: "sería ceguera de nuestra parte no reconocer el hecho de que habrá votos de ese tipo..." 43

Las dificultades del partido que plantea O'Brien, tampoco son una novedad. Todas habían sido ya denunciadas ante la Casa Blanca. El partido había perdido contacto con los electores. Su fuerza había residido en las ciudades, pero los habitantes de éstas, al mejorar su condición económica, se habían trasladado a los suburbios, en donde ya no habían sido seguidos por las organizaciones del partido. Tradicionalmente habían sido los demócratas los protectores de los desvalidos y las minorías raciales. Ahora, la más numerosa de éstas, la de los negros, no estaba ya de acuerdo con ellos.

Tampoco había contacto entre el partido y los candidatos. El DNC descuidaba a los estados y ahora necesitaba que en éstos se trabajara, no sólo por sus candidatos locales, sino también por Johnson:

\begin{abstract}
Debemos examinar los procedimientos de distribución de fondos a los candidatos demócratas para mejorar los esfuerzos pasados. La ayuda financiera a los candidatos tendría que hacerse con la suficiente antelación como para que empleen el dinero con mayor efectividad, y también con la suficiente antelación para que bagan amigos. ${ }^{44}$
\end{abstract}

O'Brien advierte -primera y única mención que al respecto encontramos-, que el candidato iba a ser hostigado y molestado a lo largo de la campaña, un pronóstico más de O'Brien, que se cum-

${ }^{43}$ Ibid., p. 28.

${ }^{44}$ Ibid., p. 32. Las cursivas son nuestras.
1 
plió tristemente en la persona de Humphrey. Las medidas de seguridad debían ser mucho más estrictas que en campañas anteriores:

Debe subrayarse que será la primera ocasión, desde la llegada de la televisión, en que un candidato a la presidencia en funciones, vaya a ser bostilizado durante su campaña en forma deliberada y sistemática. Las posibles implicaciones son de tal magnitud que exigen una atención prioritaria. Las medidas de seguridad para proteger al presidente de Estados Unidos, es obvio, deben de ser fortalecidas y no hay duda de que algunos grupos tratarán de azuzar a la policía y otros al partido, con el propósito de lograr que la fuerza pública los golpee frente a las cámaras de la televisión. Se espera una constante rechifla organizada. El trabajo de avanzada para tratar de convertirlos en multitudes entusiastas será más importante que nunca. ${ }^{45}$

Los jóvenes ocupaban el cuarto lugar entre los problemas del partido. Su número había disminuido entre los demócratas mientras que aumentaba en las filas republicanas. Necesitaban realizar encuestas que les dieran a conocer el sentir de los jóvenes hacia los partidos políticos. Tampoco se podían olvidar de las mujeres. Debía llegarles la opinión demócrata sobre Vietnam o sobre la violencia urbana. Además, recordarles que el partido las trataba en pie de igualdad con los hombres.

El problema de los negros era otro cantar. Era tan alarmante dentro de la vida nacional, que sólo un milagro los salvaría de la violencia racial en el verano del 68 . Violencia que dañaría a Johnson, el presidente bajo cuya administración más se les había favorecido. El conflicto

45 Ibid., pp. 32 y 33 . Cursivas en el texto original. racial no sólo restaría al partido los votos de los negros -por no haber quedado satisfechos con lo que se les había dado-, sino también los de aquellos blancos que se quejaban de todos los favores hechos a los negros. No se temía tanto su participación el día de las elecciones -no se preocupaban por empadronarse ni influía en ellos su prensa política que era muy mala, como la violencia de la que podían ser fácil presa aguijoneados por la demagogia de líderes como Stokely Carmichael y Rap Brown. En suma, la estrategia a seguir con los negros dependería del candidato republicanoy variaría por estados. Los demócratas sólo considerarían a aquellos en los que el voto de los negros fuera decisivo:

Los negros representan del 10 al $11 \%$ de la población, pero un porcentaje substancialmente menor del voto, y en mucbos estados su voto difícilmente tendrá efecto alguno en la elección presidencial. Uno de los primeros y más importantes proyectos en relación con el programa de operación sufragio debe ser la selección de los estados en donde el voto negro pudiera cambiar la elección de una manera $u$ otra $y$ porende, dichoproyecto debeconcentrarse en obtener ese voto. ${ }^{46}$

Hasta aquí los problemas internos del partido. Faltaba ver los que les crearan los republicanos. Aunque mucho de la campaña de éstos dependería del candidato que escogieran, se podían anticipar ya ciertos tópicos de la campaña republicana. Los republicanos se iban a presentar como el partido de la paz. O'Brien considera el efecto devastador que tendría el mostrar por la televisión los féretros de los norteamericanos muertos en Vietnam, junto a la cifra del total de los

${ }^{46}$ Ibid., p. 37. Cursivas en el original. 
muertos en guerras peleadas durante administraciones demócratas. Otros asuntos podrían ser que Johnson le había mentido al pueblo sobre lo que pasaba en Vietnam; que no podía ganar la guerra ni terminarla, ni combatir la violencia en las calles y el excesivo gasto federal. En suma, la campaña republicana sería emotiva y anti-Johnson y le vendría bien a cualquier candidato que nominaran.

Por último, O'Brien hace algunas sugerencias acerca de las convenciones primarias y nacional. Debía partirse de un análisis de las leyes que regulaban las primarias en cada uno de los estados en las que se realizaran, sin descuidar a aquellos que escogían a sus delegados por medio de convenciones estatales:

Como una generalización podría aceptarse que no hay ningún interés particular para usted [Johnson] en las elecciones primarias para presidente, pero podrían tener un efecto negativo si no se manejan en forma conveniente. Con seguridad la prensa y el público verían las primarias presidenciales como una prueba de su popularidad en el momento en que estas primarias se lleven a cabo. ${ }^{47}$

La organización de la Convención Nacional debía dejarse en manos del DNC, al que sólo supervisaría la CTF. Ésta sería una de las ventajas que tendrían sobre los republicanos; la CTF no distraería su atención de la campaña para dirigir la Convención.

O'Brien concluye que, pese a las dificultades que ha planteado, cree posible la reelección de Johnson si no se pierde el tiempo y se toman en cuenta sus sugerencias.

Este "White Paper" de O'Brien lo en-

${ }^{47}$ Ibid., p. 41. contramos entre los documentos de los legajos de Marvin Watson. A Lewis Gould le llama la atención que no se haya conservado copia de este documento en los archivos del presidente ni en el del propio O'Brien. Gould dice que fue Watson el que, en septiembre de 1966, recomendó a O'Brien con el presidente, para que coordinara las actividades políticas del DNC. Tampoco encontramos indicios de que la CTF se haya integrado. ${ }^{48}$

Ahora bien, si el proyecto de O'Brien no se siguió al pie de la letra, en el archivo de Marvin Watson encontramos una sección bajoel título "DNC-Rowe-O'BrienCrooker-Criswell Operation". Por la información contenida en ella, pensamos que esta operación integraba al equipo coordinado por Watson y que servía de enlace entre la Casa Blanca y el DNC. La información correspondiente a esta sección consta, sobre todo, de reportes enviados por los delegados políticos comentando la situación en sus estados, misma que coincide, en general, con la información que contiene el archivo político de la Casa Blanca. A través de esta correspondencia se aprecia que quien está en más estrecho contacto con Watson es Criswell, del DNC, mientras que el tan criticado Bailey nunca se dirige a Watson; con seguridad, acordaba directamente con el presidente.

Si a menudo se encuentran comentarios a favor del equipo político de Johnson, también se escuchan críticas. John P. Roche opina, con todo respeto, que Watson no podía conducir el DNC y cumplir a la vez con sus tareas en la Casa Blanca; al igual que era excesiva la carga

${ }^{48}$ Lewis Gould, "Guide to Marvin Watson files", pp. 4 y 9 . En el archivo de Watson también están las observaciones de Jim Rowe al documento de O'Brien y la respuesta de éste del 7 de noviembre de 1967. 
de O'Brien: ser director de Correos, hacer el trabajo del Congreso y "atender el almacén político". Bailey necesitaba una guía sistemática ya que no sabía ni qué color de corbata usar y parecía estar sólo de figura decorativa. De esta falta de un político encargado de cuidar "el negocio de tiempo completo", se aprovechaba Kennedy. Causa extrañeza el que O'Brien, en su "White Paper" no considerara a Kennedy como un problema para Johnson, cuando lo era para la mayoría de los hombres del presidente. Roche lamenta también la falta en esos momentos, de un Jim Farley, verdaderamente al frente del partido como antes y no como el mero consejero que era entonces. ${ }^{49}$

El 9 de octubre llega a la Casa Blanca

${ }^{45} \mathrm{John}$ P. Roche al presidente, 4 de diciembre de 1967, Archivo confidencial, PL Political Affairs Box 76. Sin embargo, trece meses después, cuando la resolución del DNC de apoyar a Johnson porque había "preferido firmemente asegurar el futuro antes que acceder a los requerimientos de la ganancia política a corto plazo" ${ }^{50} \mathrm{Comomensaje} \mathrm{político} \mathrm{que}$

Humphrey había sido derrotado, Roche defendió a O'Brien diciendo que había obrado "con total integridad" con Johnson yen la campaña de Humphrey, aunque en el ínter hubiera trabajado con Robert Kennedy. "A word edgewise...", 2 de enero de 1969, EX PL 6-2 Box 111; Watson al presidente, 24 de enero de 1968, EX PL 2 Box 87. Se reporta también: "Farley dice que es cosa segura que usted [Johnson] gane en 1968 y que muchos políticos cobardes, que hoy están dominados por el pánico, volverán a apoyar a los triunfadores el año próximo." Ben Wattenberg al presidente, 12 de septiembre de 1967, EX PL 2 Box 88.

${ }^{50}$ Harry McPherson a Watson, 9 de octubre de 1967, EX PL Box 1. Antes, Watson había presentado a Johnson una sintesis de ese discurso para su aprobación. Watson al presidente, 5 de octubre de 1967, EX PL 2 Box 88.

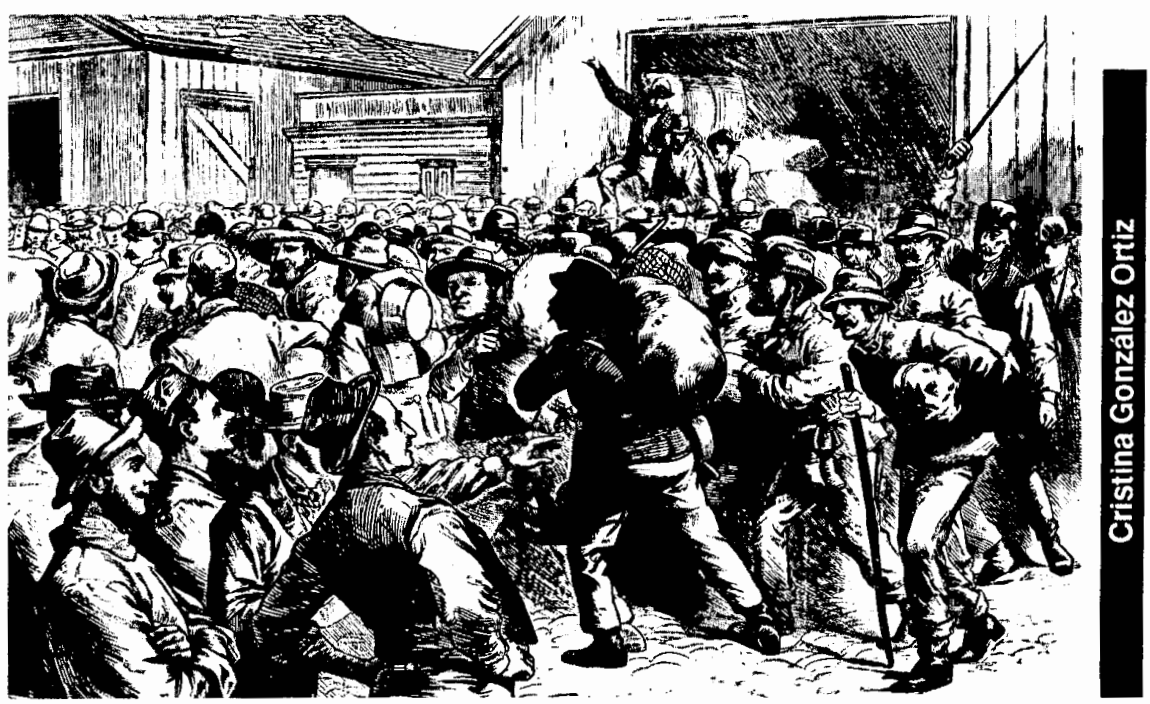


es, este pronunciamiento de Bailey no contiene las preocupaciones de O'Brien, salvo la recomendación de poner énfasis en el futuro.

A fines de ese mismo mes, Marianne Means comenta un memorándum secreto que contenía, según ella, la estrategia del DNC para la campaña del 68. Las ideas esenciales de ése le parecían provenir de Larry O'Brien, Richard Scammon y Clark Clifford. En el documento se presume que el candidato republicano será Nixon y que los ataques de los republicanos a los demócratas se dirigirían, como lo había dicho O'Brien en su "White Paper", contra Vietnam, la falta de credibilidad y el resquebrajamiento moral. Porotrolado, la propaganda se haría por televisión, dirigida a las áreas urbanas y suburbanas. Means cita textualmente:
Al término de cinco años de logros históricos sin paralelo, nos encontraremos con que el público lo acepta como algo natural y nos preguntará qué cosa tenemos para ofrecerles en el futuro...

Means concluye, a continuación, con sus propias palabras: "es obvio que los demócratas son conscientes de que no será fácil responder a estos interrogantes". ${ }^{1}$ Este memorándum no se encuentra en los legajos que revisamos, pero se trata, seguramente, de un documento semejante al "White Paper" de O'Brien.

${ }^{51}$ Marianne Means, "LBJ's campaign in motion", The News A merican, 31 de octubre de 1967. En los archivos no encontramos ni una copia ni referencias a este documento confidencial de la Casa Blanca que llegó a manos de la periodista.

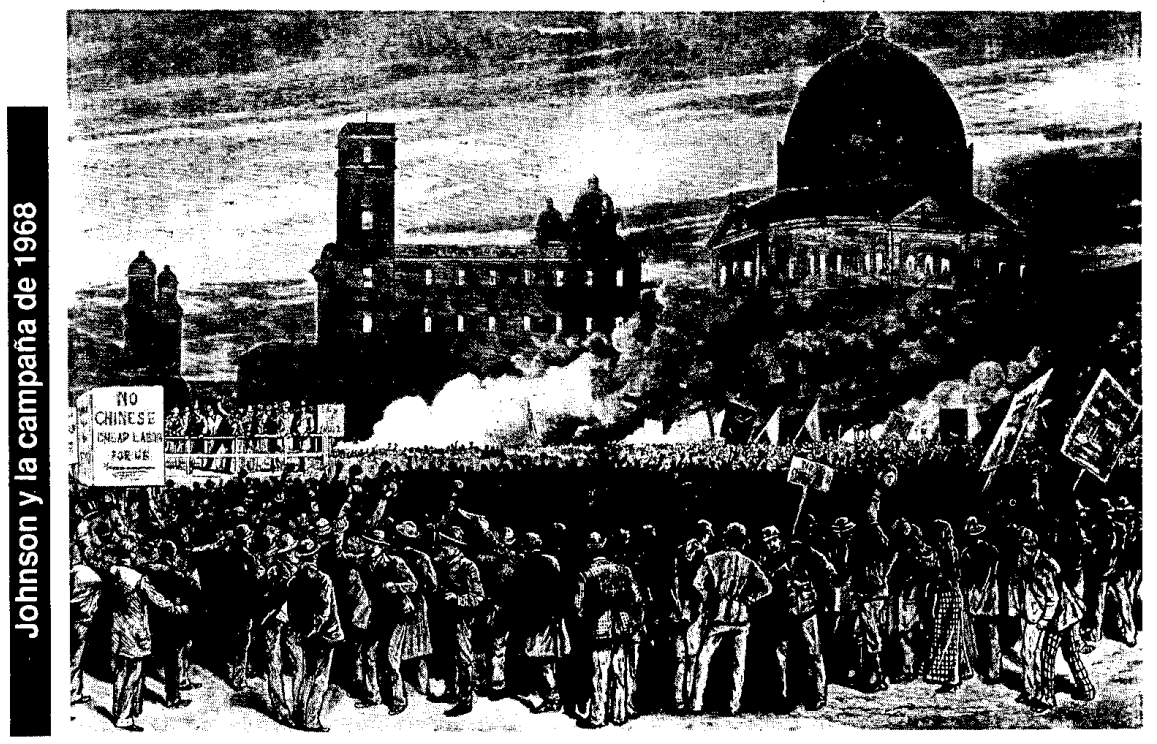


LA DIVISIÓN DEL PARTIDO DEMÓCRATA Y EL INGRESO DE ROBERT KENNEDY EN LA CONTIENDA ELECTORAL.

A fines de octubre, John Criswell del DNC pronunció un discurso durante la Conferencia Demócrata del Medio Oeste. Como era de esperarse en este tipo de eventos, se alabó en forma optimista a los demócratas y se criticó con desdén a los republicanos. Criswell tranquilizó a sus correligionarios diciéndoles que no se alarmaran ante las críticas que se le hacían a Johnson, porque el presidente hacía lo que era justo y necesario y no lo pasajero y popular. Menos aún debían preocuparlos los disidentes demócratas,

... los que preferían al senador Kennedy, al doctor Martin Luther King o al doctor Spock. Por lo menos 99 de cada cien delegados en nuestra próxima convención de Chicago se lo jugarán todo, una vez más, por "Todoel camino con LBJ". Así que no perdamos el tiempo ni gastemos nuestro aliento discutiendo este asunto ya resuelto por nuestros camaradas demócratas. $^{52}$

Por otro lado, se encuentran varios reportes llenos de confianza en Johnson. En uno de ellos se declara que McCarthy no sólo no era una amenaza sino que los favorecía al hacer que todos los demócratas cerraran filas alrededor del presidente; cerca de $90 \%$ de los delegados que lo habían apoyado en 1964 lo haría en el 68.53 Sin embargo, los informes que muestran desaliento y desesperanza superan en número a los que expresan confianza. Más que el probable candida-

\$2 "Remarks of John B. Criswell to Midwest Democratic Conference", 21 de octubre de 1967, EX PL 2 Box 88. El entrecomillado es nuestro.

s3 Robert E. Thompson al presidente, 27 de diciembre de 1967, EX PL 6-2 Box 116. to republicano, a los demócratas les preocupa su propio partido por el efecto de Vietnam en la opinión pública y el posible rompimiento de la unidad por las diferencias con McCarthy y Kennedy. Estos dos asuntos están, por supuesto, relacionados entre sí, por el apoyo que McCarthy y Kennedy daban a las "palomas" que querían la paz, contra los "halcones" de Johnson empecinados en continuar la guerra.

Así, tenemos reportes de apoyo al presidente por su política en Vietnam, como el unánime de la Conferencia Demócrata de los Estados del oeste y otros de algunos gobernadores y políticos que creían que, de vivir John F. Kennedy, estaría haciendo lo mismo que Johnson, combatiendo el comunismo en Asia. Creían, también, tener a su favor la buena impresión que habían causado las recientes elecciones realizadas en Vietnam y a las que habían acudido como observadores gente de los altos círculos políticose intelectuales. Además, el resultado de unas entrevistas realizadas por la revista Newsweek, no era sino la aprobación de la política de la Casa Blanca: "El reporte niega que toda noción de la opinión pública-como es representada por los líderes mundiales-apoye una retirada en Vietnam." 54

Abundan, también, las sugerencias que se le hacen al presidente para resolver el

${ }^{54}$ Western States Democratic Conference, 28 de agosto 1967, EX PL Box 1; Marvin Watson al presidente, 16 de octubre de 1967, Archivos de Marvin Watson, DNC, Rowe, O'Brien, Crooker Criswell Operation, Box 20. Es muy abundante la información que hày desde fines de agosto sobre los preparativos de la comisión de observadores de las elecciones en Vietnam, que culmina con las cartas de agradecimiento a Johnson de los participantes y un reporte optimista sobre el suceso. Ben Wattenberg al presidente, 14 de septiembre de 1967, EX PL 2 Box 88; Douglas Cater al presidente, 21 de noviembre de 1967, EX PL 6-2 Box 116. 
problema político que la guerra le había acarreado. Stewart L. Udall, secretario del Interior, recomendaba minimizar las disputas de la familia demócrata respecto a Vietnam: "siento que debemos limar este asunto y no agravarlo en nuestra campaña del próximo año." Robert Kintner, el amigo de Johnson, le dice que McCarthy y Kennedy difundían la creencia de que el gobierno no deseaba la paz, lo cual era una tontería, pero debían convencer a la opinión pública de que se exploraban todas las medidas para conseguir la paz, amén de que al presidente le preocupaba también el alto costo de la vida debido a la inflación. George Agree proponía desviar la atención del problema de Vietnam con programas a favor de la justicia racial y contra la violencia, además de las muy costosas para dar empleo, casa, servicios médicos y educación. Otros, como Walt Rostow, John P. Roche, y el propio Johnson, se esforzaban en convencer a sus adversarios, sobre todo intelectuales, de las bondades y tino de la política en Vietnam, al mismo tiempo que expresaban su aquiescencia para escucharsugerencias. ${ }^{55}$

En una carta del doctor Polan, quien le escribía con frecuencia a Watson, encontramos la única alusión al intenso

55 Stewart L. Udall al presidente, 28 de noviembre de 1967, EX PL Box I; R.E. Kintner al presidente, 15 de enero de 1968; George Agree a Douglas Cater, 19 de enero de 1968, EX PL 2 Box 88. Curiosamente, Agree, quien parece ser un líder estatal del Partido Demócrata, el más liberal en Estados Unidos, propone se use el slogan de "Orden y Progreso", mismo lema del sociólogo August Comte y de los "científicos" de Porfirio Díaz en México antes de la revolución de 1910. Del presidente Johnson a Marc A. McGarvey, 11 de abril de 1967; Walt Rostow a J. William Fulbright, 7 de julio de 1967; del presidente Johnson a Robert W. Gilmore, 9 de agosto de 1967, EX PL 2 Box 87; John $P$. Roche a Donald $M$. Freeman, 6 de septiembre de 1967, EX PL 6-2 Box 116; Walt Rostow a Edward J. Rozek, 15 de marzo de 1968, EX PL Box 1. desgaste emocional que la guerra de Vietnam provocaba en Johnson:

... era claro que el presidente estaba emocionalmente involucrado con la situación de Vietnam según lo expresaba en su discurso... Él debe tratar que este asunto le provoque la menor tensión posible tanto fisica como mentalmente, aunque indudablemente es una gran carga. Debe encaminarse con mesura hacia el 68 que es en sí un reto muy considerable. ${ }^{56}$

Los reportes sobre la situación del partidoen los estados tampoco eran tranquilizantes. Parecía que no contaban en California con el apoyo del ex gobernador Pat Brown, ni del lider del Congreso Jesse Unruh, amén de que éste favorecía a Kennedy. Los demócratas de Nueva York y de Nueva Jersey no estaban bien informados acerca de Vietnam, la economía y la crisis urbana porque el partido estaba muy desorganizado en esos como en otros estados. Se reconocía, también, la división entre los demócratas del sur, sobre todo, en Texas. ${ }^{57}$

Cuando Eugene McCarthy se lanzó a

${ }^{56}$ L.M. Polan a Watson, 5 de diciembre de 1967 , EX PL 2 Box 88. Es innegable que, en uno u otro momento de sus vidas, los seres humanos están sujetos a presiones emocionales, pero el sufrirlas está muy lejos de significar que se haya perdido la razón como se ha dicho de Johnson en la obra de reciente publicación y veinte años después de los sucesos narrados, de Richard Goodwin, Remembering America: avoice from the sixties, Little Brown, 1988. El récord de la actividad y las decisiones de Johnson muestra el control que ejercía sobre ellas. A principios de 1968 circuló propaganda en contra de Johnson dirigida expresamente a psiquiatras. Probablemente se refería al estado de su salud mental aunque su contenido no aparece en los archivos consultados. John Criswell a Watson, 31 de enero de 1968, EX PL 2 Box 88.

57 Iru Sprague a Watson, 7 de octubre de 1967; Bert a James R. Jones, 11 de enero de 1968, EX PL 2 Box 88 ; Fred Bohen a Joe Califano, 28 de febrero de 1968; Larry Temple a Watson, 7 de febrero de 1968, EX PL 6-2 Box 116.
1

2

\section{9}


hacer campaña para obtener la candidatura demócrata a la presidencia, pronun- ${ }^{*}$ ciándose en contra de la política de Johnson en Vietnam, Kintner aconsejó al presidente -aunque no estaba aún seguro de los motivos y objetivos de McCarthy ni del apoyo que conseguiria-, no entablar una polémica con el senador de Minnesota, misma que le daría a éste la publicidad nacional tan codiciada. Si alguien debía contestarle a McCarthy era Bailey, y a nivel político. Tampoco Roche consideraba que debiera prestarse atención a McCarthy. Confesaba además, con desenvoltura, haber corrido el rumor de que, en realidad, McCarthy trabajaba para Johnson; lo que más lo sorprendía era que un político tan astuto como Ernest Gruening, senador por Alaska y crítico de Johnson, lo hubiera creído cierto. Por otro lado, Rostow se pregunta, si ante la posición intransigente de Hanoi-que no quería hacer una sola concesión sino sólo exigía a los norteamericanos la suspensión de los bombardeos, retiro de tropas y el reconocimiento del Frente de Liberación como único representante de la gente de Vietnam del Sur-, McCarthy hubiera seguido una conducta distinta a la adoptada por la administración de Johnson. 58

Se reporta, aunque sin alarma, un tercio de los votos, cálculo del número de simpatizantes con los que contaba McCarthy en Oregon, de donde era senador Wayne Morse; en Kansas sólo un pequeño grupo. A McCarthy lo seguían los jóvenes por estar en contra de la guerra y a ellos tenían que convencer. Un confidente de Watson le dice que McCarthy no tendría

\footnotetext{
${ }^{58}$ Robert E. Kintner al presidente, 20 de noviembre de 1967, Archivos Confidenciales, FG 1 Presidente de Estados Unidos (1967) Box 16; John P. Roche al presidente, 9 de enero de 1968; Walter Rostow al presidente, 28 de noviembre de 1967, Archivos confidenciales, PL Political Affairs Box 76 .
}

arriba de un $20 \%$ en las primarias. Poco después, el triunfo de McCarthy en Minnesota no parece preocuparles; se debía a la apatía de los que estaban en la administración que rara vez votaban en las "triviales" primarias, también al celo de los jóvenes que se hacían notar, pero que no representaban a la mayoría; por último, a la "...capacidad de organización de los comunistas y de los hemi-demi-semi comunistas que han estado fuera de la circulación (y haciendo dinero) desde Henry Wallace".

No es ésta la primera ni la última vez que se refieren a la oposición con el apelativo de "comunista". Acerca del probable apoyo de Kennedy a McCarthy, no se tiene ninguna certeza, aunque se insinúa que Johnson cree que existe un acuerdo entre ellos y se alude a los delegados del partido, que con seis meses de anticipación, estaban trabajando para conseguir un buen respaldo al presidente. Sobre las primarias de New Hampshire no encontramos sino dos informes anteriores a su realización. En uno de ellos se pronostican los problemas que McCarthy le ocasionaría ahí a Johnson:

Existe un claro sentimiento antivietnamita en esta pequeña Nueva Inglaterra que puede convertir la posible candidatura del senador McCarthy en fuente de serios conflictos para el presidente Johunson.

En el otro, a escasos diez días del evento, se recomienda, aunque la posición de Johnson se consideraba sólida, moderar el ataque a los partidarios del senador por ser contraproducente y encender más los ánimos. No se encuentra comentario alguno sobre el imprevisto porcentaje de votos obtenido por McCarthy en New Hampshire. ${ }^{59}$

${ }^{59}$ James Jones a Marvin Watson, 23 de enero de 
La misma incertidumbre que se palpa entre los colaboradores de Johnson sobre la relación entre McCarthy y Kennedy, está presente con respecto a las verdaderas intenciones de este último y de los que lo postulaban, los miembros de la ADA, los "Citizens" y, sobre todo, los líderes de los trabajadores. A mediados de agosto de 1967, Joe Rauh, el presidente de la ADA y reconocido como aliado de Kennedy, presentó una propuesta de paz para Vietnam a la vez que opinaba que

... la fórmula del movimiento KennedyFulbright parece que no obtendrá un apoyo substancial, básicamente porque Kennedy probablemente irá a New Hampshire a hacer campaña en contra de esa fórmula y en favor del presidente.

Sin embargo, cuando a principios del año siguiente, la $\mathrm{ADA}$ se pronunció a favor de McCarthy, sólo se dijo que Rauh no estaba muy seguro con respecto a esta posición, pero el caso era que no había conseguido el apoyo a Johnson. ${ }^{60}$

Si bien se encuentran en los legajos muy escasos recortes de artículos periodísticos, éstos son, por lo general, favorables a la administración y de los mismos autores que no pasan de cuatro. Uno de

1968, Archivo de Marvin Watson, DNC, Rowe, O'Brien, Crooker, Criswell Operation Box 20; Robert Docking a Watson, 19 de febrero de 1968, EX PL 2 Box 89; Watson al presidente, 5 de diciembre de 1967, EX - PL 2, Box 88; al presidente, s.n., 8 de marzo de 1968, Archivos Confidenciales, PL Political Affairs Box 76; Watson al presidente, 30 de enero de 1968, Archivos de Marvin Watson, DNC, Rowe, O'Brien, Crooker, Criswell Operation Box 20; Robert E. Thompson, "Johnson's campaign", 27 de dicjembre de 1967, EX PL 2 Box 88; Marianne Means, "Marianne Means' Washington", The News American, 7 de noviembre de 1967; Charles Bartleit al presidente, 3 de marzo de 1968, EX PL 2 Box 89.

${ }^{60} \mathrm{Al}$ presidente, s.n, 16 de agosto de $1967, \mathrm{EX}$ PL 2 Box 87; James Wechsler, "ADA's vote for McCarthy", Washington Post, 12 de febrero de 1968. ellos es Victor Riesel, del que se conservan dos artículos acerca de las posibles alianzas que los líderes de los trabajadores pudieran hacer en estos críticos meses. Riesel comenta que Victor Reuther, el poderoso líder de la United Auto Workers (UAW), aunque amigo de Kennedy, aún no se decidía y no parecía estar en buenos términos con el no menos poderoso George Meany, presidente de la Federación Americana del TrabajoCongreso de Organizaciones Industriales (AFLCIO). Sin embargo, no descarta Riesel la posibilidad de que, finalmente, Reuther apoye a Johnson. Reseña, además, con detalle, el homenaje que le hizo a Meany el Comité Laboral Judío en el que no estuvo presente Kennedy y al que Johnson decidió asistir a última hora. Esto le valió ganarse el apoyo de los trabajadores, aunque no de todos; sólo dos días después, era desollado en Chicago por Galbraith, King, la UAw de Reuther y los Trabajadores Unidos del Vestido. Más tarde, en diciembre, Riesel reporta que poderosos líderes del trabajo planean acabar con Robert Kennedy; no les gustaba que éste se valiera de la ADA para sus fines políticos. Menciona, asimismo, a las ya muy conocidas gentes $d \epsilon$ Kennedy, Galbraith, Sorensen, McCarthy y Rauh. ${ }^{61}$

La decisión de la ADA de apoyar a McCarthy es vista con desconsuelo por un congresista de Texas porque ha dividido a los demócratas y ha dado una falsa idea de Johnson,

${ }^{61}$ Victor Riesel, "Reuther bolts labor's pro-Johnson political machine", "President Johnson opens campaign by personally lining up powerful Libe-

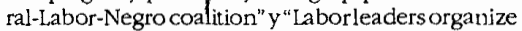
behind scenes to smash Robert Kennedy's political machine", Inside Labor, 3 de octubre, 13 de noviembre y 8 de diciembre de 1967. 
... quien más duro ha trabajado o más se ha dedicado a la causa a favor del hombre común y del pobre. Tampoco es responsable el presidente Johnson por todas nuestras enfermedades y problemas, sin embargo, las acciones de la ADA se orien$\tan$ a hacerlo aparecer así. ${ }^{62}$

John P. Roche, que había representado los intereses de Johnson en la reunión de la ADA, le comunicó que no pudieron ganarse a la UAW de Reuther porque éste noestaba en condiciones de pelea debido a la pena por la muerte de unos familiares; sin embargo, había prometido que arremetería de nuevo en mayo. Tiene Roche, además, la certeza de que Rauh trabajaba para el presidente, aunque no expresa sus razones; probablemente porque postuló a McCarthy y no a Kennedy. La opinión favorable que también se tenía en la Casa Blanca acerca del controvertido Reuther, parece confirmarla el mismo Humphrey. En una visita, Reuther le había ofrecido todo su apoyo, a la vez que criticado el respaldo de la ADA a McCarthy: "él [Reuther] pensó que esto fue erróneo e inútil. La $\mathrm{ADA}$ como expresión nacional del liberalismo ha sido seriamente dañada." 63

Aunque se tenía la certeza de que Kennedy se preparaba para algo, se desconocía su estrategia, además de que la entrada en escena de McCarthy, cambió toda la perspectiva política. En di-

\footnotetext{
${ }^{62}$ Henry B. González a Marvin Watson, 13 de febrero de 1968, EX PL Box 1.

${ }^{63} \mathrm{John}$ P. Roche al presidente, 16 de febrero de 1968, Archivos Confidenciales, PL Political Affairs Box 76; del vicepresidente al presidente, 16 de febrero de 1968, EX PL 2 Box 89. La fidelidad de Reuther parece confirmarse meses después de haber anunciado Johnson su retiro de la carrera electoral, cuando en una visita que el primero hizo a Califano, le dio a entender que apoyaria a Humphrey. Joe Califano al presidente, 22 de abril de 1968, EX PL 2 Box 89.
}

ciembre, Roche decía que Kennedy preparaba una "guerra de liberación" contra Johnson y su administración; se encontraba aún en la etapa de la guerrilla y no se decidía a pasar a la de la organización de las fuerzas unidas. La "atomización" que sufría el partido podría favorecerlo. Un mes después, se reporta que, durante su estancia en Washington, Kennedy se dedicó a hablar con los líderes políticos de la nación. La información sobre el senador desaparece en las siguientes semanas para reaparecer a mediados de marzo, en múltiples cartas de tono alarmado, justo antes del día 16, cuando Kennedy decidió lanzarse abiertamente a la campaña electoral. ${ }^{64}$

El 14 de marzo Fred Panzer expresa el temor de muchos de que Kennedy fuera a intervenir en la contienda porque dividiría a las "palomas". Al día siguiente se informa que era casi segura la entrada de Kennedy a la carrera electoral, aunque no se sabe si participará o no en las primarias. Por primera vez comienza a hablarse de cierto rasgo de la personalidad de Kennedy, que se volverá a mencionar más adelante y al que parece temerse: "Kennedy tiene casi una mística sobre su propio futuro, que él lo tiene 'todo dentro de él' y que tiene que llevarlo a cabo." 65

${ }^{6}$ John P. Roche al presidente, 4 de diciembre de 1967, Archivos Confidenciales, PL Political Affairs Box 76; John Bert a James R. Jones, 10 de enero de 1968, EX PL 2 Box 88 . En enero Johnson recibió una carta de tono muy agresivo de parte de Charles Porter, quien presidía junto con Martin Shepard el grupo "Citizens for Kennedy in 1968". En ella le dice al presidente que lo considera un "political zombie", critica a Watson y sugiere que dejen las cuestiones políticas en manos de O'Brien o de Bailey: "Déjelos responder a nuestros desafios, a discutir públicamente si usted o Bobby Kennedy deberían ser nominados por los demócratas en Chicago." Charles Porter al presidente, 5 de enero de 1968, EX PL 2 Box 88.

65 Fred Panzer a Liz Carpenter y Harry Mc- 


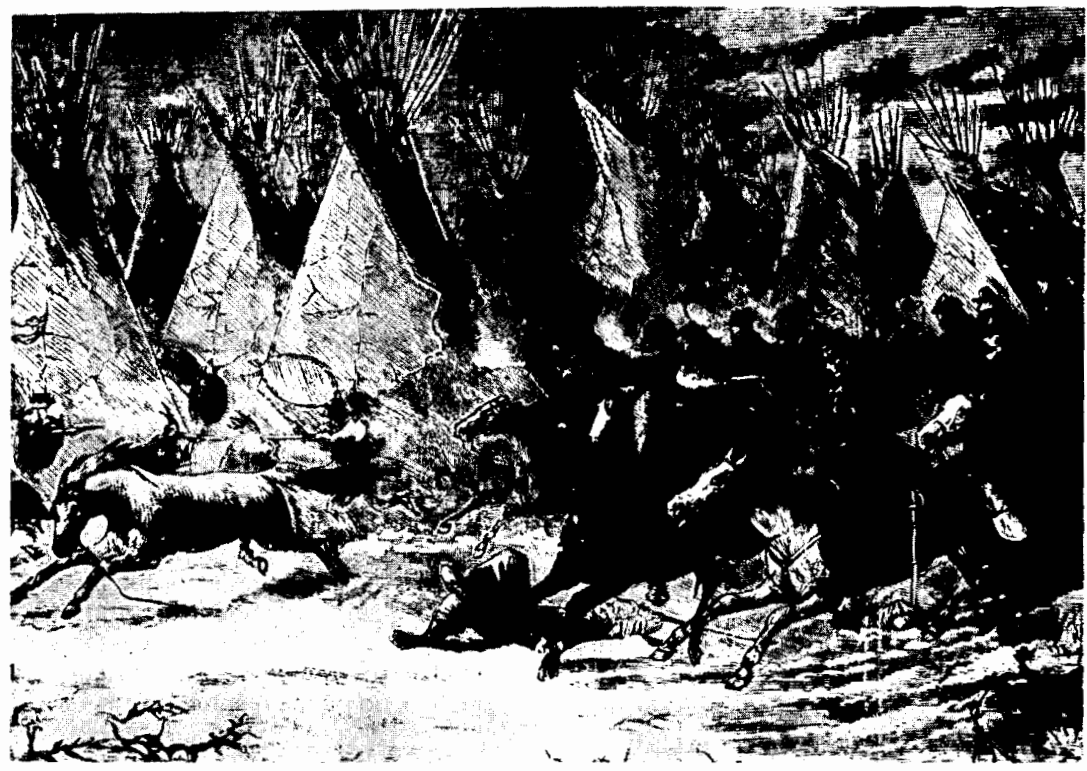

Tras el anuncio de Kennedy de participar en la contienda electoral, George Christian le informa a Johnson que se decía había sido Richard Daley, el alcalde de Chicago, el que había aconsejado a Kennedy. Pero este era un rumor que había salido del propio campo del senador para su beneficio, ya que otros informes confirmaban el apoyo de Daley a Johnson. Por otro lado, a algunos les parecía que la decisión de Kennedy favorecía al presidente:

Voy a decirle una maldita cosa: la tendencia es a favor del fortalecimiento de la gente de Johnson. El domingo pasado Kennedy tropezó en la reunión con la prensa y esto no le ayudó. Dijo que no se iba a poner a discutir sobrela personalidad

Pherson, 14 de marzo de 1968; Lloyd Hackler a Jim Jones, 15 de marzo de 1968, EX PL 2 Box 89. de uno u otro y eso fue precisamente lo que hizo. Es un tipo malvado y la gente empieza a darse cuenta de ello.

Se habla, también, de un posible retiro de Kennedy, pues al dividir a las "palomas" había labrado su propia ruina. Además de que los demócratas no veían con buenos ojos sus cambiantes puntos de vista y sus ataques al presidente. ${ }^{66}$

La división interna del partido no les hace perder de vista al posible candidato republicano. La información también es

${ }^{66}$ George Christian al presidente, 18 de marzo de 1968, EX PL Box 1. Daley le dijo a Christian que simpatizaba con "la preocupación del presidente por la guerra y la situación fiscal y dice que no sabe cómo un ser humano puede soportartanto trabajo". Christian al presidente, 29 de marzo de 1968; Mary al presidente, 20 de marzo de 1968, EX PL 2 Box 89; Fred Panzer a George Christiany Marvin Watson, 21 de marzo de 1968, Archivos confidenciales, PL Political Affairs Box 76 . 
contradictoria. A mediados de 1967 del republicanoque más se ocupan es George Romey. Probablemente porque les parecía el mejor rival, dada su conocida postura antisindical y antilaboral. También se evaluaban las posibilidades de Percy, pero tenía la desventaja de ser poco conocido. Al mismo tiempo, Panzer reporta que de mayo a junio habían bajado los puntos de Nixon y Romney y aumentado los de Reagan y Rockefeller. Sin embargo, a principios de octubre, Johnson no creía que pudiera ser Rockefeller; aunque un mes después que daba pie para pensar en que un grupo de gobernadores republicanos moderados le iban a prestar su apoyo a Rockefeller en las primarias. Tampoco hay acuerdo respecto a Nixon. Marianne Means decía a fines de octubre que Johnson sabía que el candidato republicano sería Nixon. Sin embargo, un mes después, Panzer opinaba que ya había pasado.el tiempo de ése. A fin de año Kintner seguía pensando en Rockefeller y se resistía a creer que pudiera ser Nixon. Con anticipación, llega a la Casa Blanca la noticia del posible retiro de Romney así como el reporte de las políticas que explotarían los republicanos contra los demócratas en la campaña. Seguramente no causaron sorpresa a nadie. ${ }^{67}$

67 Joe Califano al presidente, 10 de mayo de 1967 ; George Christian al presidente, 19 de junio de 1967; Fred Panzer al presidente, 28 de junio y 11 de julio de 1967, EX PL 2, Box 87; Thomas Vail al presidente, 8 de septiembre de 1967, EX PL Box 1; Marvin Watson al presidente, 5 de octubre de 1967; Stewart L. Udall al presidente, 28 de noviembre de 1967, EX PL 2 Box 88; Marianne Means, "LBJ campaign in motion", The News American, 31 de octubre de 1967; Fred Panzer al presidente, 28 de noviembre de $1967, \mathrm{EX}$ PL 2 Box 88; Robert E. Kintner al presidente, 29 de diciembre de 1967, Archivos Confidenciales, FGl Presidente de Estados Unidos (1968) Box 16; Michael

La información que las encuestas proporcionan estos meses acerca de la opinión pública sobre Johnson, Kennedy o Vietnam es muy abundante, pero, como siempre, contradictoria. Johnson, que recibía todo el tiempo información simultánea de varios canales de televisión, deseaba también conocer el sentir de la opinión pública a través de las encuestas:
últimamente las encuestas nacionales no han traído sino malas noticias para el presidente Johnson. Sin embargo, su fas- cinación por las encuestas no parece dis- minuir. Casi cada político demócrata local que lleva a efecto una de ésas, envía a la Casa Blanca copia de los resultados para que el presidente los revise personalmente. En repetidas ocasiones él mismo ha insis- tido en que no cree en la exactitud de las encuestas pero, como son tan escasas las pruebas del cambiante comportamiento público, no puede resistir consultarlas.

Por otro lado, es frecuente la queja de que las compañías privadas de encuestas no favorecían a los demócratas, como había sucedido ya en tiempos de Truman; sus resultados no coincidían con los de los diarios de mayor circulación. ${ }^{68}$

Los reportes sobre la popularidad de Johnson varían según el asunto y el momento. Todos los informes coinciden en que la guerra de Vietnam era la que más dañaba la imagen del presidente. Aunque Panzer le dice, y parece que sin

Manatos al presidente, 28 de febrero de 1968, EXPL 2 Box 89; Fred Panzer al presidente, 16 de diciembre de 1967, EX PL 2 Box 88.

${ }^{68}$ Marianne Means, "Marianne Means' Washington", The News American, 29 de agosto de 1967; Clayton Fritchey, "State of affairs", Newsday, 13 de noviembre de 1967. Fred Panzer le solicita a Watson unos datos porque estaba llevando un récord de todos los votos "anti-Vietnam". Panzer a Watson, 6 de diciembre de 1967, EX PL 2 Box 88. 
ironía, que más que su política en Vietnam, a los del este les molestaba su acento texano.

Ahora bien, si un mayor número de norteamericanos había tenido una idea más clara de lo que había sido la segunda guerra mundial, de la que ahora se tenía sobre Vietnam, eran también pocos los que en esos momentos creían poderla ganar totalmente. El asunto de la guerra presentaba además dos problemas, el del vacío de credibilidad porque el pueblo se sentía engañado por el presidente y el de la ruptura generacional, ya que los mayores de 50 años estaban con Johnson y los menores de 30 lo rechazaban rotundamente, amén de que los hombres entre los 21 y los 49 años que pagaban impuestos y podían ser reclutados tampoco lo querían. La ofensiva de Tet del 30 de enero de 1968 bajó en siete puntos el porcentaje de los que apoyaban a Johnson y los convirtió en minoría: $41 \%$ contra 47 de los que no aprobaban su política. Sin embargo, en esta última cifra, no sólo se expresaban los que rechazaban la guerra sino que el ataque de Vietnam del Norte hizo que aumentara el número de "halcones" y $10 \%$ de éstos no estaba de acuerdo con Johnson, porque no se mostraba en Vietnam todo lo agresivo que ellos hubieran querido.

Después de Vietnam, el proyecto de elevar los impuestos, la inflación, los motines y los negros constituyen la fuente principal de las quejas. Pero, paradójicamente, en las elecciones celebradas el 7 de noviembre, los demócratas derrotaron a los republicanos en las ciudades de más de 100000 habitantes, por un margen de casi tres a uno. ${ }^{69}$

69 Panzer al presidente, 16 de junio de 1967 , EXPL 2 Box 87; Panzer al presidente, 4 de octubre de 1967, EX PL. Box 1; Panzer a Ernst Goldstein,
Sobre la popularidad de Johnson, ésta se mantuvo en aumento los tres últimos meses de 1967 y en enero del 68. Dato alentador, sobre todo, si se compara con las cifras poco halagüeñas a las que había llegado a descender en agosto de 1967; este bajo nivel se había comparado con la actitud de la gente en 1964, y resultó que $54 \%$ era en agosto menos favorable hacia Johnson, o sea, tres de cada cuatro personas habían cambiado de opinión. Pero, hacia fines del 67 había optimismo y Panzer informaba que Johnson había "frenado una aguda tendencia hacia la baja y podría estarse encaminando a una posición de fortalecimiento para la elección del 68". No obstante, en febrero vuelve a ser mayor el porcentaje de los que no estaban de acuerdo con el presidente. Gallup no se alarma por estos resultados y explica que los cambios bruscos son temporales y se deben a las circunstancias, en este caso, a la ofensiva de Tet. $^{70}$

Otro asunto era la popularidad del presidente comparada con la de sus rivales demócratas. Si McCarthy no parecía afectarlo mucho, la notoriedad de Kennedy era inquietante. Enuna encuesta de Harris que incluía a demócratas y

George Christian y Marvin Watson, 21 de febrero de 1968, Archivos Confidenciales, FGl, Presidente de Estados Unidos (1968) Box 16; Panzer al presidente, 7 de marzo y 1 y 16 de febrero de 1968, EX PL 2 Box 89; Godfrey Sperling, "Johnson called vulnerable in " 68 ", The Christian Science Monitor, 31 de agosto de 1967; Tom Johnson al presidente, 27 de noviembre de 1967, EX FGl Box 16; Panzer a Watson, 16 de noviembre de 1967, EX PL 2 Box 88.

${ }^{70}$ Panzer a Watson, 3 de agosto de 1967, Archivos Confidenciales, F61, Presidente de Estados Unidos (1967) Box 16; Gallup Poll, 6 de sept iembre de 1967, EX PL Box 1; Fred Panzer al presidente, 1 de diciembre de 1967 y 28 de enero de 1968 , EX PL 2 Box 88; Fred Panzer al presidente, 15 de febrero de 1968, EX PL 2 Box 89.

.


republicanos, hecha en octubre y noviembre, la popularidad de Kennedy iba en aumento y rebasaba a Johnson. Lo apoyaban, sobre todo, jóvenes y mujeres menores de 35 años. Con respecto a Johnson, Harris señala que más que Vietnam, lo afectaba que lo consideraran "un político oportunista". Pero, además, el apoyo a Kennedy era más bien la expresión de un mero sentimiento antiJohnson. En cambio, una encuesta de Spivac le daba a Johnson ventaja sobre Kennedy, aunque éste no hacía un mal papel frente a los republicanos: tenía más puntos que Johnson frente a Nixon y Rockefeller, aunque tampoco lograba superarlos. En enero, cuando mayor popularidad alcanzó Johnson, aventajaba a Kennedy 73 puntos sobre 59 y, por lo que se refiere a las ciudades, en un gran número de ellas el presidente era el preferido, mientras que Kennedy sólo lo superaba en Chicago. Hacia febrero aparecieron otras cifras también favorables a Johnson, 52 frente a 40 de Kennedy; mucho mayor la ventaja ante McCarthy, 71 a 18. No encontramos más datos sobre la relación Johnson-Kennedy, sino hasta pocos días antes de que el presidente comunicara su decisión de retirarse. $^{71}$

El material sobre encuestas es también muy abundante, entre aquellas que se refieren a la relación demócratas-republicanos. En abril de 1967, Johnson aventajaba a Nixon pero era superado por Romney y, hacia agosto, $71 \%$ consideraba que los republicanos tenían más oportunidad de ganar que los demó-

${ }^{71}$ Fred Panzer al presidente, 1 y 5 de diciembre y 27 de noviembre de 1967; Spivac Poll, 20 de diciembre de 1967; Gallup Poll, 20 de octubre de 1967; Fred Panzer al presidente, $10,12,16$ y 4 de enero de 1968, EX PL 2 Box 88; Fred Panzeral presidente, 2 de febrerode 1968 , EX PL 6-2 Box 116. cratas; éstos sólo.alcanzaban 38\%. Poco después, en una encuesta de Gallup, aparece como favorito Rockefeller ante Johnson, 48-46; aunque Harris empata estas cifras en caso de presentarse Johnson con Humphrey; es más, le da ventaja al presidente si lleva como mancuerna a Kennedy, 52-48. Hacia octubre, Rockefeller había aumentado su ventaja; pero en noviembre Panzer le comunica al presidente que Nixon iba a la cabeza de los contendientes republicanos y, lo que era una muy buena noticia, Johnson lo superaba en popularidad. A su vez, en una encuesta realizada en enero en California, Johnson aventajaba a todos los posibles candidatos republicanos, menos a Rockefeller quien le llevaba ahí una ventaja muy considerable, 54 a 37 . Sin embargo, en el mismo día, una encuesta a la que se da mucha importancia, en el condado de Strafford, porque la opinión de éste coincidía frecuentemente con los resultados finales de las elecciones, revela que el único candidato que puede ganarle a Johnson es Nixon. La popularidad de éste continuaba en aumento, pero a fines de febrero, aunque Gallup lo empata con Johnson, le da en cambio el triunfo a Rockefeller en caso de contender con el presidente. Por supuesto, tampoco se pierde de vista a Wallace y se preguntaban a quién beneficiaría su participación; a fines de febrero se creía que a Johnson. Además por esas mismas fechas, se tiene el dato de que, tanto si participaba Wallace como si no, el presidente tenía ventaja sobre Nixon y. Rockefeller. ${ }^{72}$ Poco después, el 16 de marzo, como ya se dijo, Kennedy decidió entrar en la carrera electoral.

\footnotetext{
${ }^{72}$ Fred Panzer al presidente, 21 de abril de 1967, EX PL 2 Box 87; Gallup Poll, 8 de agosto de 1967, EX PL Box 1; Fred Panzer al presidente, 15 y 22 de septiembre, 2 y 3 de octubre y 17 de noviembre de 1967 y 7,19 y 30
} 
LA DECISIÓN DE LYNDON

B. JOHNSON DE NO PARTICIPAR

EN LA CAMPAÑA DEL 68

El gran volumen y la calidad de la información correspondientes a las tres últimas semanas del mes de marzo, muestran, indudablemente, la inquietud y la inseguridad que se vivieron en la Casa Blanca.

El disgusto producido por el aviso de Kennedy de buscar la nominación presidencial debió ser muy grande. Si la Casa Blanca no refleja hacia el exterior una imagen de gran preocupación, el presidente piensa que las interrogantes sobre las perspectivas de los demócratas este año son prematuras, aunque ninguna

de enero de 1968, EX PL 2 Box 88; Fred Panzer al presidente, 20 de febrero de 1968, EX PL 2 Box 89; Gallup Poll, 25 de febrero de 1968, EX PL Box 1; Fred Panzer al presidente, 24 de febrero de 1968, EX PL Box 89. división es favorable para un partido político. En cambio, es elocuente la anotación de puño y letra de Watson al telegrama que le comunicaba que Lord Harlech consideraba mejor candidato a Kennedy que a Johnson: "Dígale a Harlech que se ocupe de sus asuntos y que Londres no tiene qué decirnos..."73

Tras la decisión de Robert Kennedy se recibieron en la Casa Blanca algunas cartas de apoyo al presidente entre los días 18 y 20 de marzo, pero su número no llama la atención y menos si lo comparamos con el de las recibidas en otras ocasiones. Por otro lado, entre los papeles del grupo encabezado por Rowe, encargado de.la campaña electoral, aparecen entre los días 25 y 27 numerosas

${ }^{73}$ George Christian a Lloyd Hackler, 20 de marzo de 1968; Telegram "With Kennedy", 17 de marzo de 1968, EX PL 2 Box 89.

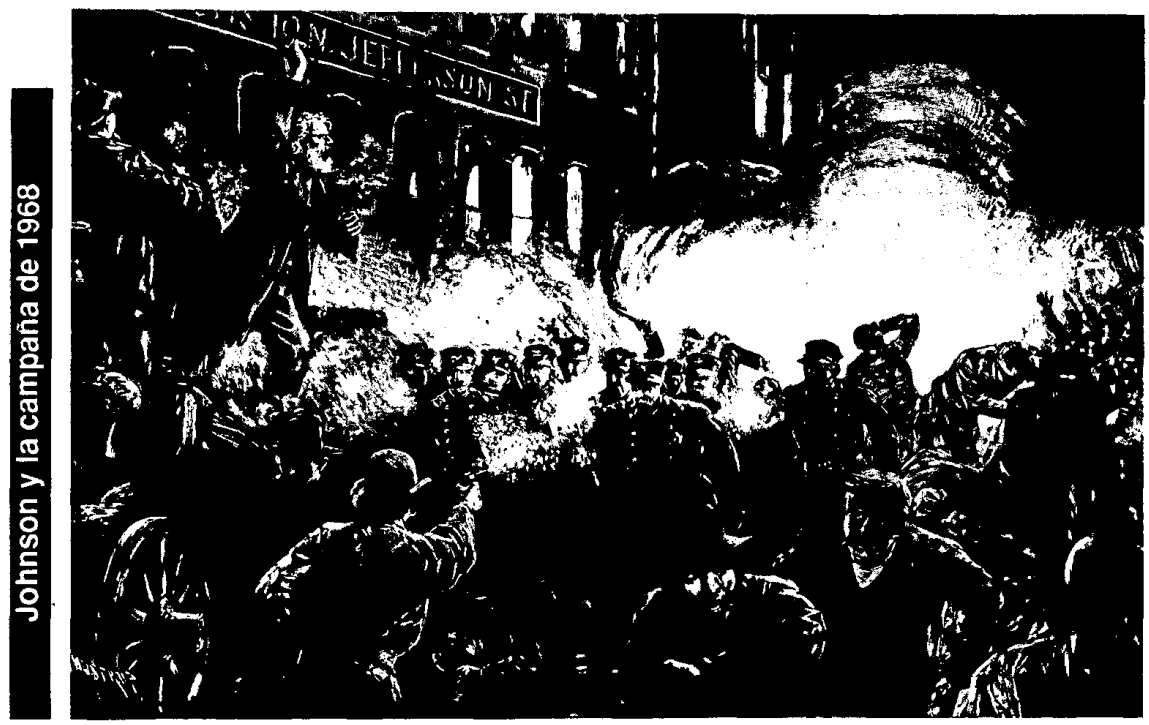


cartas de gobernadores las cuales, por la coincidencia de su contenido, parecen ser más bien la respuesta a una solicitud, la de dar su anuencia para formar parte del Comité Nacional de Ciudadanos por Johnson y Humphrey. Sorprende en ellas el que, si bien muchos de los remitentes dan su apoyo a Johnson, algunos expresen abiertamente que primero está la política de su estado y que los candidatos locales no tienen oportunidad de ganar si se comprometen con el presidente. ${ }^{74}$

Si el anuncio de Kennedy pudo no sorprender a Johnson y a algunos de sus más cercanos colaboradores, sí alarmó a muchos de sus seguidores. De ahí el cambio de tono en los juicios contra Kennedy y en los proyectos que se presentan para combatirlo. Por un lado, se palpa el miedo real a un complot comunista, no muy bien definido, que se asocia con Kennedy y Fulbright: "...los comunistas de los años treinta están saliendo del marasmo... y hoy día obtienen sus nombramientos como delegados a la convención con un solo propósito, destrozar al Partido Demócrata."

Por otro lado, hay una aproximación mas real a la personalidad de Kennedy. Observan su gran atractivo de tipo emocional, mismo que lo acercaba más a un Presley o a los Beatles que a un candidato a la presidencia: " $¿ P u e d e$ imaginarse a John F. Kennedy permitiendo que le mesen los cabellos y lo maltraten? ¿Realmente el pueblo quiere un presidente al que pueda apretar, empujar, pellizcar o abrazar?"

Esto hacía a Robert Kennedy muy popular entre sus seguidores, que no eran los mismos de McCarthy:

${ }^{74}$ Steve McNichols, Harold E. Hughes y Mills E. Godwin a Marvin Watson, 25, 26 y 27 de marzo de 1968, Archivos Marvin Watson, DNC, Rowe, O'Brien, Crooker, Criswell Operation Box 20.
McCarthy y Kennedy obtienen su apoyo de grupos marcadamente diferentes. El atractivo de R.F.K. se da entre la gente joven de unos 20 años, mujeres, gente con educación inferior a la universitaria y católicos[...]El apoyo de McCarthy proviene de gente mayor, hombres, universitarios y protestantes.

Sobre este mismo asunto, Busby le escribiría a Johnson en abril, cuando ya el presidente había anunciado que se retiraba de la campaña: "Bobby está sacando ventaja de su [Johnson] limitación de movilidad; ha estado explotando a las masas con el objeto de crear la impresión de que él es el único con 'carisma'."75

No obstante las observaciones, críticas y denuncias sobre Kennedy que hacen los colaboradores de Johnson, éstas no ocupan el lugar más importante de la correspondencia en esos días. Parece, más bien, como si las fallas de la campaña se hubiesen magnificado al perderse la confianza por la amenaza de Kennedy. Las voces de alarma no sólo provienen de la propia Casa Blanca y del grupo encabezado por Rowe para la campaña, sino también de la gente de fuera. Se refieren a un sinfin de asuntos: organizar a los veteranos de Vietnam; no olvidarse de la Oficina Nacional de los Ciudadanos Jóvenes; pedirle ayuda a Lucy y Linda, las hijas del presidente, para ganarse a los jóvenes, tanto demócratas como republicanos; dar información sobre Vietnam al público en general y a los delegados demócratas para que convencieran a su gente. Amén de que, después de tantos meses de preparación,

75 Joe Califano al presidente, 8 de marzo de 1968, EX PL 6-2 Box 116; Douglas Cateral presidente, 28 de marzo de 1968; Bill Crook a Marvin Watson, 27 de marzo de 1968, EX PL 2 Box 89; Fred Panzer al presidente, 2 de febrero de 1967, EX PL 6-2 Box 116; Horace Busby al presidente, 26 de abril de 1968, EX PL 2 Box 89. 
a los delegados no les había llegado la información prometida. Dicha información ni siquiera circulaba en los altos niveles:

Una de las quejas [...] era que ni el Comité Demócrata ni nadie más parecía estar préparando las notas para los discursos con las que tanto los senadores como los otros oradores públicos se auxilian para las campañas.

Tampoco se aprovechaban la radio y la televisión como se había planeado. Yquedaba por hacer mucha labor de propaganda entre los congresistas. No faltan, por supuesto, propuestas para alcanzar la pazen Vietnam y recuperar así a la opinión pública. ${ }^{76}$

En los últimos días de marzo encontramos una serie de comunicados que tratan de poner remedio a la falta de organización que, parece, sólo puede atribuirse a la confianza que se tenía. Confianza difícil de comprender, después de las serias advertencias de O'Brien, entre otros, de lo difícil que sería ganar las elecciones. $\mathrm{Si}$ el presidente, como dicen algunos, mantuvo en secreto por mucho tiempo, no se sabe cuánto, su decisión de no participar en la campaña electoral, esto sólo lo sabían unos cuantos y no puede servir como disculpa el hecho de que nose

${ }^{76}$ Fred Panzer al presidente, 19 de marzo de 1968, EX PL 2 Box 89; Stuart Ross a Cecil Burney, 26 de marzo de 1968; Walt Rostow al presidente, 22 de marzo de 1968, Archivos Marvin Watson, DNC Rowe, O'Brien, Crooker and Criswell Operation Box 20; George Christian al presidente, 29 de marzo de 1968; Averrell Harriman al presidente, 27 de marzo de 1968; Joe Califano al presidente, 27 de marzo de 1968; Michel Manatos a Marvin Watson, 8 de marzo de 1968; Lloyd Hackler a Watson, 9 de marzo de 1968, EX PL Box 89; Liz and Bess al presidente, 19 de marzo de 1968, archivos Marvin Watson, DNC, Rowe, O Brien, Crooker and Criswell Operation Box 20; James G. Patton al presidente, 25 de marzo de 1968; Barefoot Sanders al presidente, 20 de marzo de 1968, EX PL 2, Box 89. trabajara. No deja de ser paradójico el que, momentos antes del retiro del presidente, se hubieran puesto a trabajar tan febrilmente por él.

El 23 de marzo, George Christian todavía no sabía a quién encauzar a las personas que ofrecían su ayuda para la campaña, y preguntaba si al DNC o a Rowe. Sin embargo, cinco días después le dijo a un voluntario que no podían utilizar sus servicios porque el presidente aún no decidía si buscaría o no la reelección: "hasta que haya tomado una decisión sobre esto no podemos echar mano de nuestros esfuerzos para la campaña". No se sabía, tampoco, quién estaba encargado de contestar los ataques de la oposición. En esos días Watson aprobó un plan para coordinar la defensa con O'Brien y otros asesores como Douglas Cater y Larry Temple. ${ }^{77}$

Otro ejemplo muy elocuente del descuido de la campaña y del temor que les provocó el que Kennedy fuera a participar en la contienda, es la improvisación de última hora. La noche del sábado 23 , en una reunión en casa de Liz Carpenter, se les ocurre a Watson, Christian y Cater, entre otros, crear un grupo de intelectuales y artistas, "Thinking people for L.B.J.", además de otro de mujeres destacadas en el gabinete y el Congreso, para contrarrestar la fuerza de Kennedy y McCarthy. Este asunto no era nuevo, ya se había tratado meses antes, pero, por lo visto, no se había hecho nada; probablemente porque se minimizó la amenaza de Kennedy. ${ }^{78}$

\footnotetext{
77 George Christian a Marvin Watson, 23 de marzo de 1968; George Christiana Allen Siles, $28 \mathrm{de}$ marzo de 1968, EX PL 2 Box 89; Memorándum, s.n., 27 de marzo de 1968, Archivos Marvin Watson, DNC, Rowe, O'Brien, Crooker and Criswell Operation Box 20; Larry Temple al presidente, 26 de marzo de 1968, EX PL 2 Box 89.

${ }^{78}$ Douglas Cater al presidente, 25 de marzo de 1968, EX PL 2 Box 89.
} 


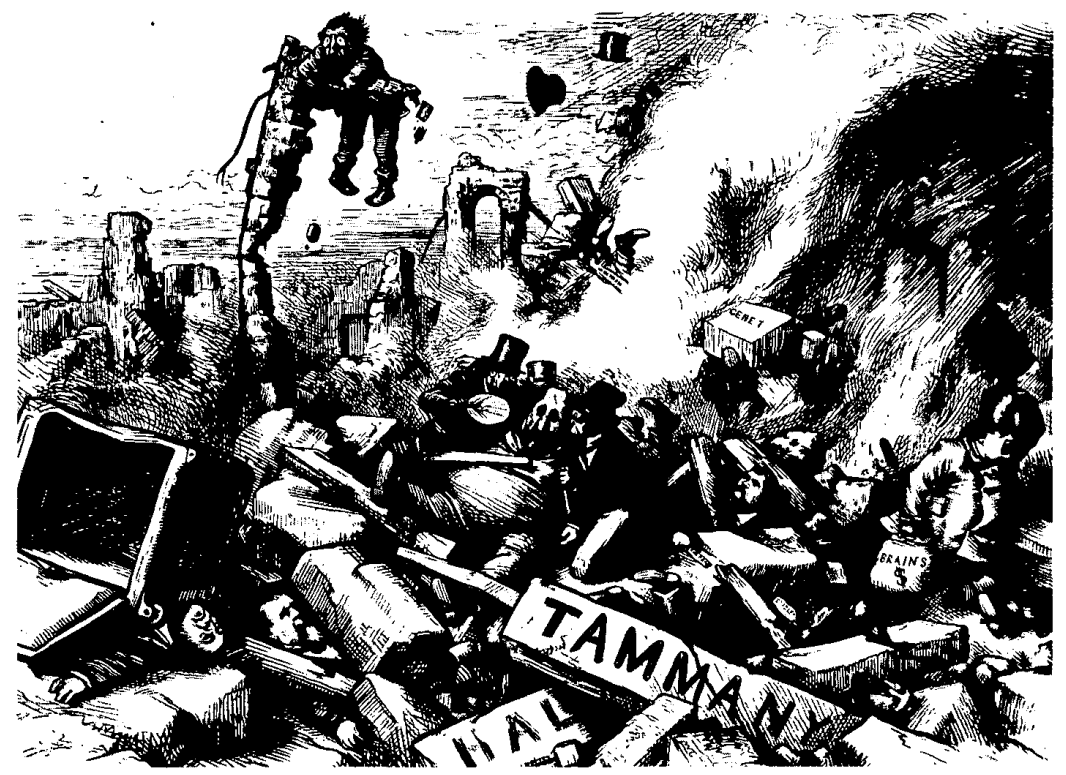

Ahora, si como se ha escrito, Johnson no pensaba reelegirse por motivos de salud, estaba muy lejos de descuidar su imagen. Para una presentación pública, quería contar con el doble de la gente que había apoyado a Kennedy en Nueva York; quería también, por supuesto, seguir informado acerca de su popularidad. El 29 y el 30 de marzo llegaron a la Casa Blanca los resultados de las encuestas que se harían públicas el 31 de marzo. Su significado no auguraba nada bueno para el presidente. El trabajo de Johnson era aprobado por sólo $36 \%$ contra 52 . Su actuación en Vietnam salía peòr librada, era rechazada por $63 \%$. Frente a los otros contendientes demócratas, Johnson tenía $43 \%$, pero sumados Kennedy y McCarthy, lograban 52. Por otro lado, frente a Nixon y Rockefeller, Kennedy obtenía un mejor puntaje que Johnson.
Ninguno de estos resultados podía alentar al presidente a buscar la reelección. ${ }^{79}$

Hemos ya citado informes que se referían a la anticipación, hasta de seis meses, con la que se había comenzado a hacer campaña entre los demócratas en diversos estados. Pero no en todos. En Wisconsin no se había hecho "absolutamente nada". La excusa que se daba de semejante apatía era que no creían que el presidente fuera a participar en la campaña. Además, según esta fuente, no era ése el único lugar en el que tal rumor corría. Por otro lado, otro informe decía

79 Vaughn Davis Bornet, The presidency of Lyndon B. Jobnson, The United Press of Kansas, 1983, pp. 289-305; Memorándum a Marvin Watson, s.n., 23 de marzo de 1968, Archivos Marvin Watson, DNC, Rowe, O'Brien, Crooker and Criswell Operation Box 20; Fred Panzer al presidente, 29 y 30 de marzo, (2) 1968, EX PL 2 Box 89. 
que era la gente de Kennedy la que propalaba en Wisconsin, Maryland, Queens y otros lugares, que Johnson no buscaría la presidencia. También algunos reporteros de la revista Time dudaban de la intención del presidente de buscar la reelección. ${ }^{80}$

Sin embargo, el día 28 , en una extensa carta, Cater le dice a Johnson que debían mejorar la imagen que presentaba de un "angry, embittered and isolated leader" por la de un presidente activo. Le sugiere visitar, de hecho, todo lo visitable en el país, salvo las instalaciones militares. No se pueden negar la franqueza y la buena intención de Cater. Así, le recomienda aprovecharse de la Marcha de los Pobres que organizaba Martin Luther King en Washington. También, "no importacuán cansado pudiera ser el recorrido de un museo o la ida a un concierto, su significado no dejaría de ser notado por el electorado."

Tenía arreglado, además, que el 1 de abril apareciera en el New York Times y otros periódicos importantes, una página completa pagada por destacadas personalidades en todas las ramas del quehacer artístico, cultural, científico, etc., que diria "We are withyou Mr.President". No cabe duda de que Cater estaba convencido de que Johnson buscaría la nominación por el Partido Demócrata. ${ }^{81}$

Pero si Califano y Cater le seguían haciendo recomendaciones a Johnson, el tono de la última carta de Jim Rowe, antes del mensaje de Johnson, es muy distinto. Hay oculto en ella un cierto reclamo, porque Rowe duda ya de las

${ }^{80}$ James Rowe al presidente, 28 de marzo de 1968, EXPL 2 Box 89; Joe Califano al presidente, 27 de marzo de 1968, EX FG 11-8-1/ Califano 7-1-67 Box 75.

${ }^{81}$ Douglas Cater al presidente, 28 de marzo de 1968, EX FG1 Box, 18 y 26 de marzo de 1968, EX PL 2 Box 89 . verdaderas intenciones del presidente:

El hecho es que la gente empieza a creer que usted no va a lanzarse. He intentado una serie de respuestas en cada uno de estos casos. Sin embargo, es claro para mí que aún así, dejaba un sentimiento de duda. La única respuesta efectiva parecía ser mi comentario sobre el hecho que "Si yo hubiera tenido alguna duda de que usted se lanzaba, la habría perdido ya el día que Bob Kennedy anunció su postulación, porque usted no le iba a entregar la candidatura a Bobby". Sin embargo, este tipo de comentario tiene muy mal efecto entre nuestra gente. Algunos me dicen que estos rumores salen de la propia Casa Blanca. ${ }^{82}$

Rowe tenía razón, algo se había filtrado de la propia Casa Blanca y fue confirmado por Johnson el domingo 31: no buscaría la nominación demócrata para las elecciones de ese año. Con todo y que eso significaba entregarle a Kennedy el liderazgo demócrata. Ni la escasa correspondencia de los muy pocos que escribieron lamentando la decisión del presidente ni los resultados de las encuestas sobre ésa, contradijeron lo atinado de la conducta de Johnson. Su mensaje fue aprobado por $70 \%$ contra $23 \%$; tres puntos más del $67 \%$ que, en esa misma encuesta, estaba a favor de suspender los bombardeos en Vietnam. ${ }^{83}$

Si en general, como se dijo, los documentos confirman la interpretación his-

82 James Rowe al presidente, 28 de marzo de 1968, EX PL. 2 Box 89. El entrecomillado es nuestro. En esta carta también se refiere Rowe a lo que la gente de Kennedy decía a los hombres del presidente: "Johnson no va a competiry si se comprometen conél ustedes parecerán bastante necios si para entonces no tienen candidatos. Manténganse indefinidos y manténganse sin compromiso."

${ }^{83}$ Memorándum, s.n., 2 de abril de 1968, EX PL 2 Box 89. 
toriográfica sobre las políticas de Johnson y del DNC, en el caso de su retiro, hay una tesis que rechaza que ése haya sido provocado por los acontecimientos anteriores a su anuncio. En The presidency of Lyndon B. Johnson, ${ }^{84 .}$ Vaughn Davis Bornet dedica muchas páginas a demostrar, con una serie de evidencias, que Johnson tenía decidido desde mucho tiempo atrás, no buscar la presidencia en 1968, debido a los problemas de tipo cardiaco que padecía y que guardó en secreto cuanto se pudo. La queja que se escuchaba los últimos meses de que el presidente no hacía campaña parece confirmar la tesis de Bornet. Sin embargo ¿con qué objeto se mantuvo en secreto la verdadera intención de Johnson? ¿Por qué no se retiró desde antes y permitió que Humphrey se preparara mejor? Por otro lado, la excusa de la mala salud del presidente nunca se empleó. ¿Se creía, acaso, que no era conveniente que el pueblo se enterara de que su presidente estaba enfermo? Johnson mismo había mostrado con orgullo a los periodistas la cicatriz que le había deja do una intervención quirúrgica, gesto que le valió más críticas que comprensión, más por ser poco refinado que por otra cosa. Indudablemente, la salud de Johnson no era buena; sus médicos le vaticinaron los años de vida que de hecho vivió, cuatro más después de dejar la presidencia ${ }^{85}$ Pero, insistimos, si por su salud había pensado en no ocupar la presidencia otros cuatro años más, pudo haberlo dicho antes y no esperar a ver su imagen tan devaluada y su popularidad tan disminuida frente a Kennedy. Es probable

${ }^{84}$ Véase nota 79.

8s Bornet, Presidency, 1983, pp. 297-298.

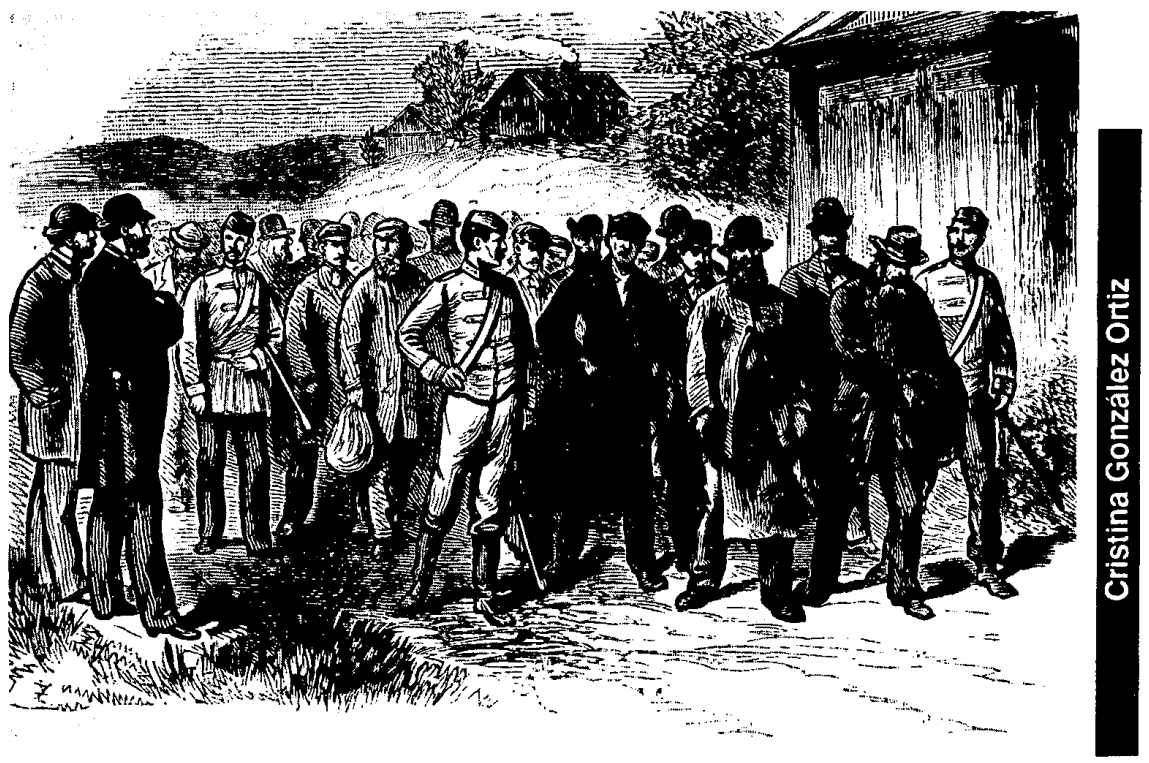




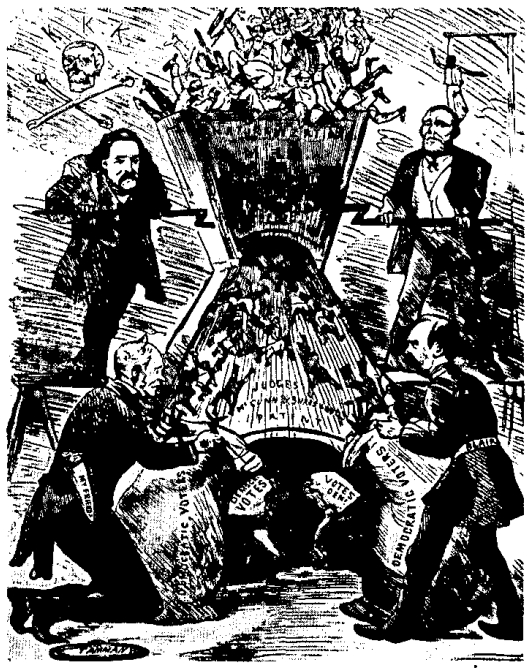

que creyera que sólo él podía mantener la unidad del Partido Demócrata. Esperaba ver salvada ésta y luego dejar que Humphrey lo sucediera. Fue una desgracia el que Kennedy se lo impidiera.

Ahora bien, de ser cierto que Johnson había decidido retirarse con mucha anticipación a su anuncio, el secreto fue muy bien guardado. Tres días antes de revelarse, Rowe aún no sabía cuáles eran las verdaderas intenciones de Johnson y, por los documentos encontrados, nada parece indicar que Marvin Watson las conociera. En la reunión ya mencionada de la noche del 23 de marzo, Watson, junto con Cater y Christian, estaban en verdad entusiasmados con el proyecto del grupo.

Días después Cater continuaba haciendo planes, aunque Christian ya decía que el presidente aún no decidía si buscaba o no la nominación. Otro personaje enigmático es O'Brien. Es notable la ausencia de su correspondencia en los archivos. No sabemos si sospechaba o no del retiro de Johnson, pero permaneció con el presidente hasta el anuncio del 31 de marzo. Fue entonces cuando se marchó a colaborar con Kennedy para regresar unos meses después, tras la muerte del senador, a dirigirle una desafortunada campaña a Humphrey. En suma, los documentos no nos arrojan luz sobre las verdaderas intenciones de Johnson, sólo muestran que la entrada de Robert Kennedy en la contienda electoral y la baja popularidad del presidente, coincidieron con su retiro.

En noviembre del año anterior, se había recibido en la Casa Blanca una carta para el presidente:

El país está rico y gordo y aun así el pueblo está descontento. Por el momento este es un becho máspsicológico quepolítico. Pero las encuestas tienen razón. El presidente es muy vulnerable... en los buenos tiempos la gente está obsesionada con sus temores por los impuestos, por la inflación, por los negros, por la guerra. Mucha gente se siente humillada por la guerra, por el sentimiento de que no podemos golpear a un pequeño país... Hay un gran deseo por un cambio de estado de ánimo, probablemente más que por un cambio de hombres. La gente parece percibir que sus vidas no tienen sentido ahora que gozan de bienestar y esperan que el gobierno les provea de todo. ${ }^{86}$

Era pedirle demasiado a Lyndon $B$. Johnson. Le había otorgado al pueblo norteamericano inmensosbeneficios con la mayor legislación social y económica jamás aprobada en otra época. Era entonces pedirle demasiado que también hiciera realidad todos sus sueños.

${ }^{86}$ Tom Johnson al presidente, 27 de noviembre de 1967, EX FG 11-2-67 Box 16. Cursivas en el original. 


\section{SECUENCIA}

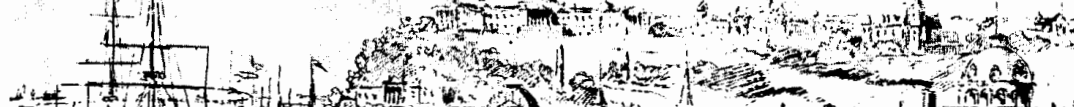

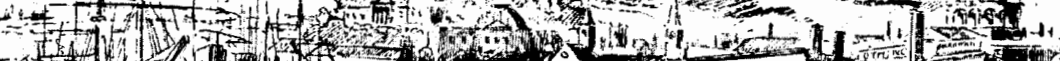

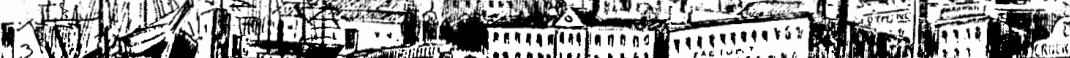

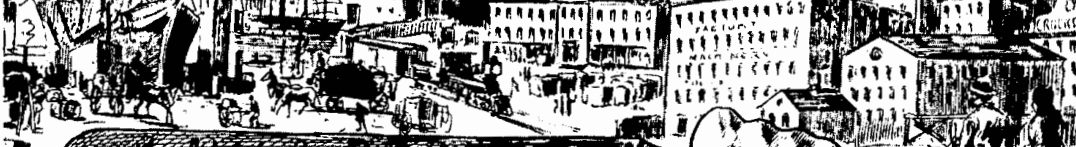

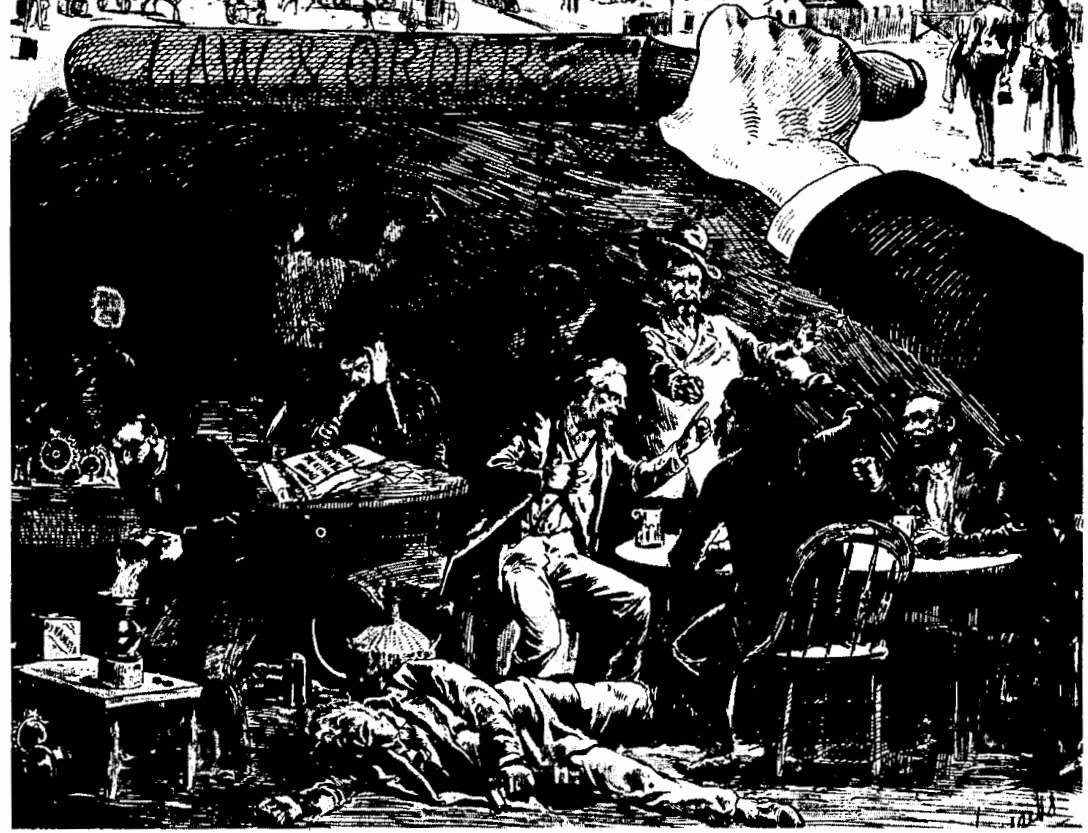

